Cite this: Phys. Chem. Chem. Phys.

Received 18th March 2014, Accepted 14th May 2014

DOI: $10.1039 / c 4 c p 01180 e$

www.rsc.org/pccp $2014,16,13340$

\section{Calcium-43 chemical shift and electric field gradient tensor interplay: a sensitive probe of structure, polymorphism, and hydration $\dagger$}

\author{
Cory M. Widdifield, ${ }^{\text {ab }}$ Igor Moudrakovskił ${ }^{\mathrm{ac}}$ and David L. Bryce ${ }^{{ }^{a}}$
}

\begin{abstract}
Calcium is the 5th most abundant element on earth, and is found in numerous biological tissues, proteins, materials, and increasingly in catalysts. However, due to a number of unfavourable nuclear properties, such as a low magnetogyric ratio, very low natural abundance, and its nuclear electric quadrupole moment, development of solid-state ${ }^{43} \mathrm{Ca} N \mathrm{NR}$ has been constrained relative to similar nuclides. In this study, 12 commonly-available calcium compounds are analyzed via ${ }^{43} \mathrm{Ca}$ solid-state NMR and the information which may be obtained by the measurement of both the ${ }^{43} \mathrm{Ca}$ electric field gradient (EFG) and chemical shift tensors (the latter of which are extremely rare with only a handful of literature examples) is discussed. Combined with density functional theory (DFT) computations, this 'tensor interplay' is, for the first time for ${ }^{43} \mathrm{Ca}$, illustrated to be diagnostic in distinguishing polymorphs (e.g., calcium formate), and the degree of hydration (e.g., $\mathrm{CaCl}_{2} \cdot 2 \mathrm{H}_{2} \mathrm{O}$ and calcium tartrate tetrahydrate). For $\mathrm{Ca}(\mathrm{OH})_{2}$, we outline the first example of ${ }^{1} \mathrm{H}$ to ${ }^{43} \mathrm{Ca}$ cross-polarization on a sample at natural abundance in ${ }^{43} \mathrm{Ca}$. Using prior knowledge of the relationship between the isotropic calcium chemical shift and the calcium quadrupolar coupling constant $\left(C_{Q}\right)$ with coordination number, we postulate the coordination number in a sample of calcium levulinate dihydrate, which does not have a known crystal structure. Natural samples of $\mathrm{CaCO}_{3}$ (aragonite polymorph) are used to show that the synthetic structure is present in nature. Gauge-including projector augmentedwave (GIPAW) DFT computations using accepted crystal structures for many of these systems generally result in calculated NMR tensor parameters which are in very good agreement with the experimental observations. This combination of ${ }^{43} \mathrm{Ca}$ NMR measurements with GIPAW DFT ultimately allows us to establish clear correlations between various solid-state ${ }^{43} \mathrm{Ca}$ NMR observables and selected structural parameters, such as unit cell dimensions and average $\mathrm{Ca}-\mathrm{O}$ bond distances.
\end{abstract}

\section{Introduction}

Calcium is present in various chemical compounds and biological systems. For example, intracellular calcium-binding proteins such as calbindin, calretinin, and calmodulin are important for calcium ion transport and for cellular regulation processes. ${ }^{1-4}$

\footnotetext{
${ }^{a}$ Department of Chemistry and Centre for Catalysis Research and Innovation, University of Ottawa, 10 Marie Curie Pvt., Ottawa, Ontario, Canada. E-mail: dbryce@uottawa.ca; Fax: +1 613562 5170; Tel: +16135625800 ext. 2018

${ }^{b}$ Université de Lyon, Institut des Sciences Analytiques (CNRS, ENS-Lyon, UCB Lyon 1), Centre de RMN à Très Hauts Champs, 5 rue de la Doua, 69100, Villeurbanne, France. E-mail: cory.widdifield@ens-lyon.fr; Fax: +33 4788967 61; Tel: +33426233888

${ }^{c}$ Steacie Institute for Molecular Sciences, NRC, 100 Sussex Drive, Ottawa, K1A OR6, Canada

$\dagger$ Electronic supplementary information (ESI) available. See DOI: 10.1039/ c4cp01180e

\# Current address: Max-Planck-Institute for Solid State Research, Heisenbergstraße 1, 70569 Stuttgart, Germany.
}

Likewise, calcium occurs in a variety of minerals and glasses, and is present at a level of about 400 ppm in sea water. ${ }^{5}$ Calciumcontaining materials find applications as high temperature superconductors, $^{6-9}$ in catalysis, ${ }^{10-15}$ in hydrogen storage ${ }^{16,17}$ and in solid-state proton conductors. ${ }^{18}$ In light of this wide array of interesting applications, which in theory could be probed using calcium solid-state nuclear magnetic resonance (SSNMR) experiments, development of the spectroscopy of the only NMR-active nuclide of calcium (i.e., ${ }^{43} \mathrm{Ca}$ ) remains somewhat lethargic ${ }^{19-21}$ due to complications which arise when attempting to perform such experiments. To date, the vast majority of systems studied by ${ }^{43} \mathrm{Ca}$ SSNMR are inorganic materials with high calcium content by mass. ${ }^{19,20}$ This is not to say that ${ }^{43} \mathrm{Ca}$ NMR experiments have never been employed to study more calcium-dilute (by mass) systems, as a number of years ago, solution ${ }^{43} \mathrm{Ca}$ NMR experiments using isotopically enriched samples were used to probe the active sites in a variety of calcium-binding proteins. ${ }^{22-24}$

Thus far, it has been beyond question that if one wishes to perform ${ }^{43}$ Ca SSNMR experiments, the most debilitating factor 
is the very low natural abundance of the ${ }^{43} \mathrm{Ca}$ nuclide $(0.135(2) \%),{ }^{25}$ which unfortunately is the only stable calcium nuclide that is also NMR active. As alluded to above in the studies on calciumbinding proteins, isotopic enrichment is an option which may be pursued, but it is rather expensive, as sample costs for $60 \%$ isotopic enrichment may potentially run in excess of $\$ 400$ per milligram. ${ }^{19,26}$ As well, unlike familiar spin-1/2 nuclei such as ${ }^{1} \mathrm{H}$ and ${ }^{13} \mathrm{C},{ }^{43} \mathrm{Ca}$ possesses a quadrupolar nucleus $\left(I\left({ }^{43} \mathrm{Ca}\right)=7 / 2\right)$. The nuclear electric quadrupole moment $(Q)$ associated with any quadrupolar nucleus will couple with the electric field gradient (EFG) at the nuclear site. This resulting quadrupole interaction (QI) has been demonstrated to have significant importance in the characterization of a diverse array of systems. ${ }^{27-31}$ At the same time, as SSNMR experiments are typically (and most conveniently) performed on powdered samples, the orientation-dependence of the QI-perturbed Zeeman interaction in a powdered sample results in NMR signal broadening. This creates a situation where the feeble ${ }^{43} \mathrm{Ca}$ NMR signal becomes distributed over a range of frequencies and hence could be buried in the noise.

While ${ }^{43} \mathrm{Ca}$ enrichment offers the most significant degree of ${ }^{43} \mathrm{Ca}$ NMR signal enhancement, if one does not wish (or is unable) to pursue enrichment, it is worth noting that the magicangle spinning (MAS) technique has been used on several occasions to detect ${ }^{43} \mathrm{Ca}$ SSNMR signals at natural abundance. Likewise, at natural abundance there is often no other reasonable option than performing experiments within a very high external magnetic field $\left(B_{0}\right)$ to reduce second-order line shape broadening due to the QI and to boost the nuclear spin polarization. ${ }^{32}$ It is not surprising that coupling high-field data acquisition with MAS is probably the optimal strategy when performing experiments on non-enriched samples. In addition, when performing experiments at natural abundance in ${ }^{43} \mathrm{Ca}$, large amounts (i.e., several hundreds of milligrams to even grams) of sample are often required, but it appears that reduced mass samples may be evaluated at natural abundance if one uses a microcoil approach. ${ }^{33}$ For systems where one wishes to balance cost, experimental NMR sensitivity, and sample amount, it is likely preferable to modestly enrich the material in ${ }^{43} \mathrm{Ca}$ (ca. 5-10\%). Regardless, the sensitivity boost afforded by MAS experiments comes at the expense of the removal (or at least in the apparent reduction) of a number of anisotropic interactions, such as magnetic shielding anisotropy and the direct dipole-dipole coupling between NMR-active spins. Although not of significance in the systems studied here, one may envision cases where small $J$-coupling values (e.g., $\left.J\left({ }^{43} \mathrm{Ca},{ }^{17} \mathrm{O}\right)\right)$ could potentially be measured using samples enriched in both ${ }^{43} \mathrm{Ca}$ and ${ }^{17} \mathrm{O}$, but this is expected to be very challenging. According to recent reviews of the ${ }^{43} \mathrm{Ca}$ SSNMR literature, ${ }^{19-21}$ only a handful of attempts have been made to quantify calcium chemical shift anisotropy (CSA), which is the experimentally-observable form of magnetic shielding anisotropy. As knowledge of a given nuclide's CSA is of substantial utility in characterizing the local bonding environment (in addition, there is considerable evidence that the isotropic calcium chemical shift value $\left(\delta_{\text {iso }}\right)$ gives insight into both the coordination number and the average $\mathrm{Ca}-\mathrm{O}$ bond distance in a variety of simple calciumcontaining materials), ${ }^{20,34-37}$ we have undertaken the present study with the aim of characterizing calcium CSA in several common materials, with and without ${ }^{43} \mathrm{Ca}$ enrichment. To enhance the potential of observing calcium CSA, and also to increase the experimental sensitivity, many of the measurements relied upon the use of a very large $B_{0}$ of $21.1 \mathrm{~T}$.

Herein, we present ${ }^{43} \mathrm{Ca}$ SSNMR results for 12 common calcium-containing compounds: $\mathrm{Ca}(\mathrm{OH})_{2}, \alpha$-calcium formate, $\mathrm{CaCl}_{2} \cdot 2 \mathrm{H}_{2} \mathrm{O},( \pm)$-calcium tartrate tetrahydrate, calcium acetate monohydrate, calcium levulinate dihydrate, $\mathrm{CaSO}_{4} \cdot 2 \mathrm{H}_{2} \mathrm{O}$, $\mathrm{CaCrO}_{4}, \mathrm{CaTiO}_{3}, \mathrm{Ca}\left(\mathrm{NO}_{3}\right)_{2}, \mathrm{CaH}_{2}$, and two naturally-occurring samples of $\mathrm{CaCO}_{3}$ (both aragonite polymorph). Depending on the system, experiments have been performed either at natural abundance in ${ }^{43} \mathrm{Ca}$, or with moderate enrichment ( $c a .7 \%$ in ${ }^{43} \mathrm{Ca}$ ). We establish links between the calcium CSA, as well as the values of the Euler angles which relate the EFG and CSA principal axis systems (PASs), with changes in the local calcium environment (i.e., 'tensor interplay'). In cases where high-quality structural data were available, we performed gauge-including projector augmented-wave (GIPAW) density functional theory (DFT) calculations to complement the experimental SSNMR findings. While demonstrated upon ${ }^{43} \mathrm{Ca}$ enriched materials on a few occasions, ${ }^{38,39}$ we also briefly consider the substantial signal enhancement that cross-polarization (CP) from the ${ }^{1} \mathrm{H}$ spin network to the ${ }^{43} \mathrm{Ca}$ spins at their natural abundance may afford.

\section{Experimental}

\section{A. Sample preparation}

Samples of $\mathrm{Ca}(\mathrm{OH})_{2}$, calcium levulinate dihydrate $\left(\mathrm{Ca}\left(\mathrm{C}_{5} \mathrm{H}_{7} \mathrm{O}_{3}\right)_{2}\right.$. $2 \mathrm{H}_{2} \mathrm{O}$ ), $\mathrm{CaCrO}_{4}, \mathrm{CaTiO}_{3}$, and $\mathrm{CaH}_{2}$ were obtained from SigmaAldrich, while $\alpha$-calcium formate $\left(99 \%, \alpha-\mathrm{Ca}\left(\mathrm{CHO}_{2}\right)_{2}\right)$ and $\mathrm{CaCl}_{2}$. $2 \mathrm{H}_{2} \mathrm{O}$ were obtained from Fluka. To prepare racemic calcium tartrate tetrahydrate $\left(( \pm)-\mathrm{Ca}\left(\mathrm{C}_{4} \mathrm{H}_{4} \mathrm{O}_{6}\right) \cdot 4 \mathrm{H}_{2} \mathrm{O}\right)$, a literature procedure was followed with minor modifications. ${ }^{40}$ For details of the procedure, see the ESI, $\dagger$ additional experimental. The received $\mathrm{CaTiO}_{3}$ demonstrated poor crystallinity, so before NMR measurements it was calcined at $1450{ }^{\circ} \mathrm{C}$ for $48 \mathrm{~h}$. For the synthesis of ${ }^{43} \mathrm{Ca}$ enriched materials, enriched ${ }^{43} \mathrm{CaCO}_{3}\left(57 \%\right.$ in ${ }^{43} \mathrm{Ca}$; Trace Isotopes, Toronto) was used. Due to the small amount of available ${ }^{43} \mathrm{Ca}$ enriched material $(50 \mathrm{mg})$, it was diluted with a fine powder of natural calcite such that the ${ }^{43} \mathrm{Ca}$ enrichment was about $7 \%$. The carbonate was then calcined at $1200{ }^{\circ} \mathrm{C}$ in a platinum crucible. The obtained ${ }^{43} \mathrm{Ca}$-enriched lime was exposed to $\mathrm{D}_{2} \mathrm{O}$ vapor, with its conversion to ${ }^{43} \mathrm{Ca}(\mathrm{OD})_{2}$ controlled gravimetrically. About one quarter of the obtained ${ }^{43} \mathrm{Ca}(\mathrm{OD})_{2}$ was neutralized with diluted acetic acid, and the solvent was allowed to slowly evaporate at room temperature, resulting in a powder of ${ }^{43} \mathrm{Ca}$-enriched calcium acetate monohydrate. Anhydrous ${ }^{43} \mathrm{Ca}\left(\mathrm{NO}_{3}\right)_{2}$ was isolated by drying the solution obtained from neutralizing ${ }^{43} \mathrm{Ca}(\mathrm{OD})_{2}$ with $1 \mathrm{M} \mathrm{HNO}_{3}$ at room temperature, followed by gradually increasing the temperature to $200{ }^{\circ} \mathrm{C}$ and keeping the powder at this temperature until the measured mass was constant. Enriched ${ }^{43} \mathrm{Ca}^{33} \mathrm{SO}_{4} \cdot 2 \mathrm{H}_{2} \mathrm{O}$ was made by simple precipitation from a solution of ${ }^{43} \mathrm{Ca}\left(\mathrm{NO}_{3}\right)_{2}$ and $\mathrm{K}_{2}{ }^{33} \mathrm{SO}_{4}$ $\left(49(1) \%\right.$ in ${ }^{33} \mathrm{~S}$ ). The two natural samples of $\mathrm{CaCO}_{3}$ (aragonite 
polymorph) were obtained by powdering a single river clam pearl of about $5 \mathrm{~mm}$ in diameter and a small branch of less than $1 \mathrm{~cm}$ of a common Ivory Bush coral. The pearl was obtained from a craft store in Ottawa, while the coral was collected during a field trip to Cuba.

While most of these materials are stable and available, or may be prepared with high purity, additional ${ }^{13} \mathrm{C}$ SSNMR experiments were performed, where possible, to further confirm sample purity (see $\mathrm{ESI} \dagger$ for ${ }^{13} \mathrm{C}$ SSNMR results). In most cases, powder X-ray diffraction (pXRD) measurements were performed (see ESI $\dagger$ for pXRD experimental details and diffractograms). Before performing the ${ }^{43} \mathrm{Ca}$ SSNMR experiments, all samples were gently ground and tightly packed into $7 \mathrm{~mm}$ o.d. Bruker $\mathrm{MAS} \mathrm{ZrO}_{2}$ rotors, $10 \mathrm{~mm}$ glass tubes, or $14 \mathrm{~mm}$ rotors from Revolution NMR LLC (Fort Collins, CO).

\section{B. Solid-state ${ }^{43} \mathrm{Ca}$ NMR}

Data were primarily acquired at the National Ultrahigh-field NMR Facility for Solids in Ottawa using a standard bore Bruker AVANCE II spectrometer operating at $B_{0}=21.1 \mathrm{~T}\left(\nu_{0}\left({ }^{1} \mathrm{H}\right)=900.08 \mathrm{MHz}\right.$; $\left.\nu_{0}\left({ }^{43} \mathrm{Ca}\right)=60.58 \mathrm{MHz}\right)$. Additional experiments were performed at the University of Ottawa using a wide bore Bruker AVANCE III spectrometer operating at $B_{0}=9.4 \mathrm{~T}\left(\nu_{0}\left({ }^{1} \mathrm{H}\right)=400.17 \mathrm{MHz}\right.$; $\left.\nu_{0}\left({ }^{43} \mathrm{Ca}\right)=26.93 \mathrm{MHz}\right)$ or a wide bore Bruker AVANCE spectrometer operating at $11.75 \mathrm{~T}\left(\nu_{0}\left({ }^{43} \mathrm{Ca}\right)=33.66 \mathrm{MHz}\right)$. Experiments were also performed at the National Research Council Canada (Montreal road campus in Ottawa, ON) using a wide bore Bruker AVANCE III spectrometer $\left(B_{0}=9.4 \mathrm{~T}\right)$ or a standard bore Bruker AVANCE III spectrometer $\left(B_{0}=11.75 \mathrm{~T}\right)$. At $21.1 \mathrm{~T},{ }^{43} \mathrm{Ca}$ NMR experiments generally used $7 \mathrm{~mm}$ probes: either a Bruker low- $\gamma$ X MAS probe or a home-built HX static probe. In select cases where ${ }^{1} \mathrm{H}$ decoupling was not needed, a $10 \mathrm{~mm}$ homebuilt solenoid probe was used. At $B_{0}=11.75 \mathrm{~T}$, experiments used either a $6 \mathrm{~mm}$ Varian T3 HX MAS probe with low- $\gamma$ accessory, a $10 \mathrm{~mm}$ Bruker X static probe, or a $10 \mathrm{~mm}$ homebuilt HX static probe. At $9.4 \mathrm{~T}$, experiments largely used $7 \mathrm{~mm}$ probes: either a Bruker HX MAS probe or a Bruker HX static probe, although in selected cases, MAS experiments used a re-built $14 \mathrm{~mm}$ Chemagnetics probe equipped with a stator from Revolution NMR LLC. Unless specified otherwise, ${ }^{43} \mathrm{Ca}$ SSNMR spectra were referenced to $1 \mathrm{M}$ or $2 \mathrm{M} \mathrm{CaCl}_{2}$ (aq) $\left(\delta\left({ }^{43} \mathrm{Ca}\right)=0.0 \mathrm{ppm}\right)$, and non-selective $\pi / 2$ pulse length calibrations were performed using a saturated aqueous solution of $\mathrm{CaCl}_{2}$. We checked for consistency between the $1 \mathrm{M}$ and $2 \mathrm{M}$ $\mathrm{CaCl}_{2}$ (aq) reference solutions, and find no significant difference between chemical shifts measured against one standard solution versus the other. For further details, see the ESI, $\uparrow$ Table S1. Unless stated otherwise, for ${ }^{43} \mathrm{Ca}$ SSNMR experiments, the non-selective pulses were scaled by a factor of $1 /(I+1 / 2)=1 / 4$ to ensure that they were central-transition selective. ${ }^{41}$

The ${ }^{43} \mathrm{Ca}$ SSNMR data were often obtained using the simple Bloch decay experiment under either MAS or static (i.e., stationary sample) conditions. Typical parameters varied depending upon whether the sample was enriched in ${ }^{43} \mathrm{Ca}$ or not. As such, selected acquisition details are provided in many of the figure captions, and in further detail in Table S1 of the ESI. $\dagger$ For certain experiments on $\mathrm{Ca}(\mathrm{OH})_{2}, \mathrm{CP}$ experiments from ${ }^{1} \mathrm{H}$ nuclei were successful. Other experiments relied upon signal enhancement techniques using double frequency sweeps (DFS) ${ }^{42}$ or frequency-shifted Gaussian rotor-assisted population transfer (FSG-RAPT). ${ }^{43}$ Where relevant, ${ }^{1} \mathrm{H}$ decoupling was applied during data acquisition under static conditions, although the sharpening of spectral features was modest. Calcium-43 spin-lattice relaxation time $\left(T_{1}\right)$ measurements were performed at $21.1 \mathrm{~T}$ for all available ${ }^{43} \mathrm{Ca}$-enriched materials using the saturation-recovery method with an MAS frequency of $5 \mathrm{kHz}$. The ${ }^{43} \mathrm{Ca} T_{1}$ values were also estimated for several natural abundance samples using 3 to 5 Bloch decay experiments. A mixed Gaussian/Lorentzian apodization function was applied prior to Fourier transformation of the time-domain data. Subsequent analytical line shape modeling was carried out using WSolids1, ${ }^{44}$ while in selected cases, numerical simulations were performed with SIMPSON. ${ }^{45}$ For numerical simulation details, see the ESI, $\dagger$ additional experimental section.

\section{Quantum chemical computations}

Computations of EFG and nuclear magnetic shielding tensors were performed with the GIPAW DFT method, as implemented in CASTEP (v. 4.1 or 5.5$).{ }^{46-49}$ Input files were typically generated

Table 1 Crystal structure data for the compounds of primary focus in this study

\begin{tabular}{|c|c|c|c|c|c|c|c|}
\hline Compound & Lattice system & Space group & Ca sites & Ca symmetry & Ca c.n..$^{a}$ & $\bar{r}_{\mathrm{Ca}-\mathrm{O}}^{b} / \AA$ & Structure reference \\
\hline $\mathrm{Ca}(\mathrm{OH})_{2}$ & Trigonal & $P \overline{3} m 1$ & 1 & $\overline{3} m$ & 6 & 2.369 & 54 \\
\hline Calcium acetate $\cdot \mathrm{H}_{2} \mathrm{O}$ & Triclinic & $P \overline{1}$ & 2 & 1,1 & 6,7 & $2.393(80), 2.404(73)$ & 55 \\
\hline$\alpha$-Calcium formate & Orthorhombic & $P c a b$ & 1 & 1 & 7 & $2.418(85)$ & 56 \\
\hline$( \pm)$-Calcium tartrate $4 \mathrm{H}_{2} \mathrm{O}$ & Triclinic & $P \overline{1}$ & 1 & 1 & 8 & $2.448(41)$ & 57 \\
\hline Calcium levulinate $2 \mathrm{H}_{2} \mathrm{O}$ & - & - & $1^{c}$ & - & $8^{c}$ & - & - \\
\hline $\mathrm{CaCl}_{2} \cdot 2 \mathrm{H}_{2} \mathrm{O}$ & Orthorhombic & $P b c n$ & 1 & 2 & 6 & $\mathrm{n} / \mathrm{a}$ & 58 \\
\hline $\mathrm{CaCO}_{3}$ (aragonite) & Orthorhombic & Pmcn & 1 & $m$ & 9 & $2.527(83)$ & 59 \\
\hline $\mathrm{CaSO}_{4} \cdot 2 \mathrm{H}_{2} \mathrm{O}$ & Monoclinic & $C 2 / c$ & 1 & 2 & 8 & $2.454(91)$ & 60 \\
\hline $\mathrm{CaCrO}_{4}$ & Tetragonal & $I 4_{1} /$ amd & 1 & $\overline{4} m 2$ & 8 & $2.440(64)$ & 61 \\
\hline $\mathrm{CaTiO}_{3}$ & Orthorhombic & Pbnm & 1 & $m$ & 6 & $2.46(11)$ & 62 \\
\hline $\mathrm{Ca}\left(\mathrm{NO}_{3}\right)_{2}$ & Cubic & $P a \overline{3}$ & 1 & $\overline{3}$ & 6 & 2.502 & 63 \\
\hline $\mathrm{CaH}_{2}$ & Orthorhombic & Pnma & 1 & $m$ & 9 & $\mathrm{n} / \mathrm{a}$ & 64 \\
\hline
\end{tabular}

${ }^{a}$ Calcium first coordination sphere coordination number. ${ }^{b}$ Average calcium-oxygen first coordination sphere distance for systems where only oxygen atoms are present in this coordination sphere. The subsequent number in brackets is the standard deviation when a distribution of distances is present. ${ }^{c}$ Arrived at in the present study by conducting ${ }^{13} \mathrm{C}$ and ${ }^{43} \mathrm{Ca}$ solid-state NMR experiments. 
Table 2 Experimental ${ }^{43} \mathrm{Ca}$ EFG and CS tensor parameters for various calcium-containing systems, including selected prior accounts ${ }^{a}$

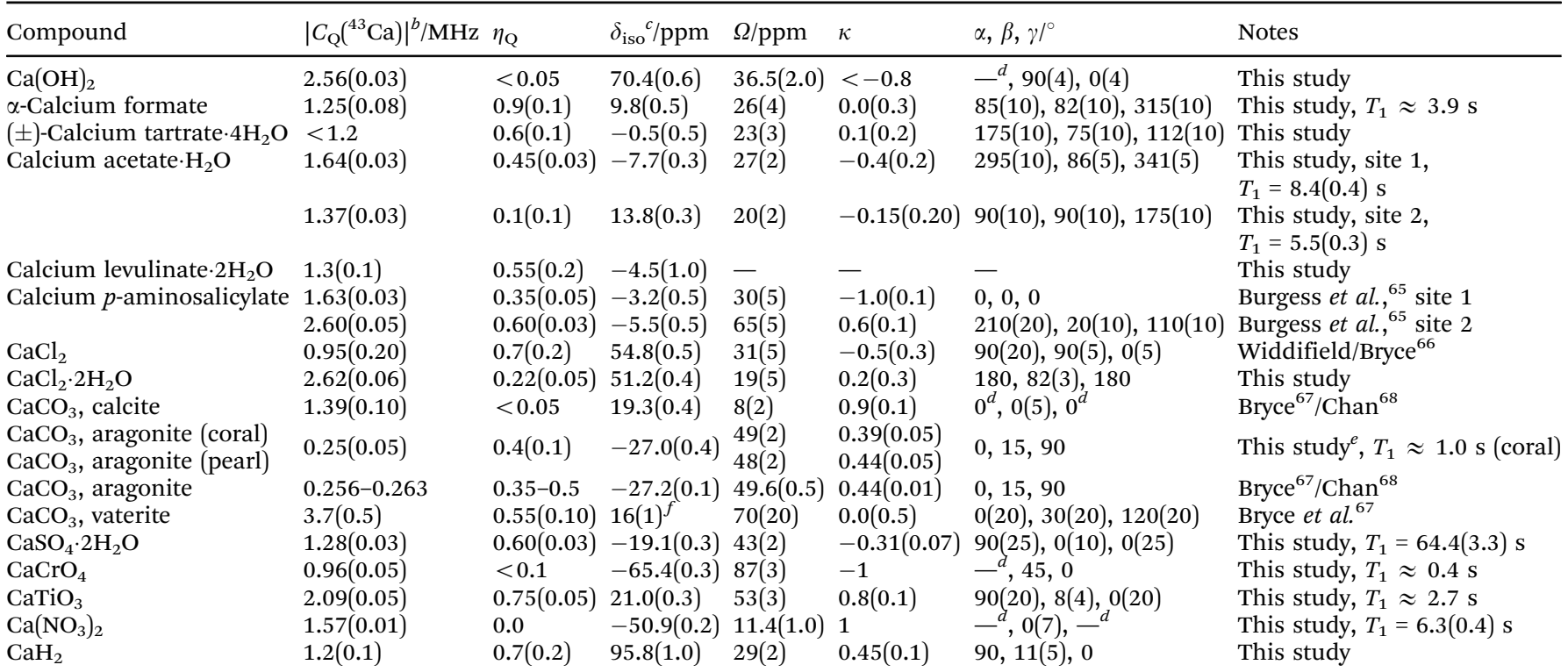

${ }^{a}$ Measurement errors are in parentheses with parameter definitions as follows: $\left|V_{33}\right| \geq\left|V_{22}\right| \geq\left|V_{11}\right| ; C_{\mathrm{Q}}=e Q V_{33} / h ; \eta_{\mathrm{Q}}=\left(V_{11}-V_{22}\right) / V_{33} ; \delta_{11} \geq \delta_{22} \geq$ $\delta_{33} ; \delta_{\text {iso }}=\left(\delta_{11}+\delta_{22}+\delta_{33}\right) / 3 ; \Omega=\delta_{11}-\delta_{33} ; \kappa=3\left(\delta_{22}-\delta_{\text {iso }}\right) / \Omega$. The Euler angles $\alpha, \beta$, and $\gamma$ define the relative orientation between the EFG tensor PAS and the CS tensor PAS. For further discussion, see ref. 69. ${ }^{b}$ While $C_{\mathrm{Q}}$ may take any real value, $\left|C_{\mathrm{Q}}\right|$ is typically measured experimentally using solidstate NMR. ${ }^{c}$ Calcium chemical shifts are relative to ca. $1 \mathrm{M}$ or $2 \mathrm{M} \mathrm{CaCl}_{2}$ in $\mathrm{H}_{2} \mathrm{O}\left(\delta_{\text {iso }}\left({ }^{43} \mathrm{Ca}\right)=0.0 \mathrm{ppm}\right) .{ }^{d}$ Parameter does not influence $\mathrm{NMR}$ spectrum due to symmetry of the interaction tensors for this system. ${ }^{e}$ EFG tensor parameters and isotropic chemical shifts were consistent between both natural samples. Euler angles included in static line shape models are from the computational results of ref. $67 .{ }^{f}$ Value corrected for consistency with current chemical shift scale.

a
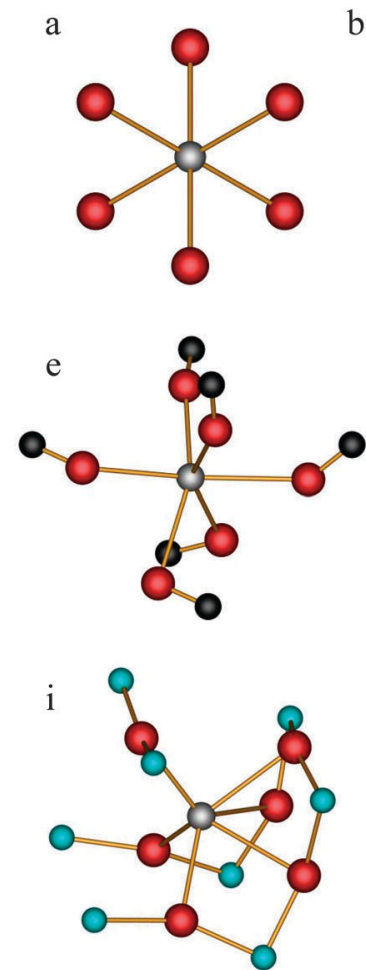

b
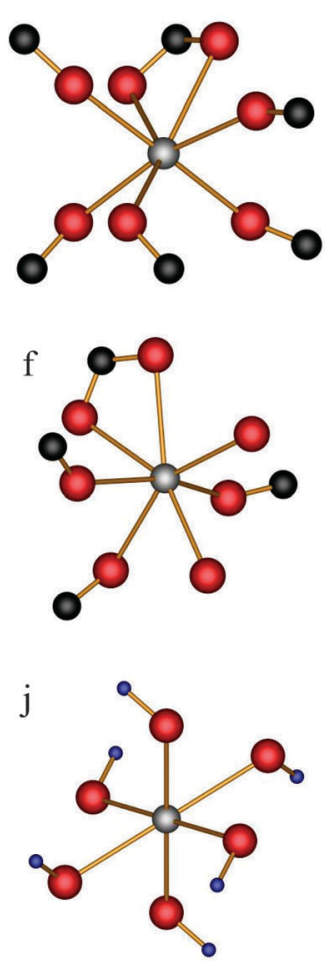

c

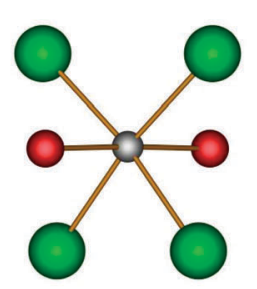

g

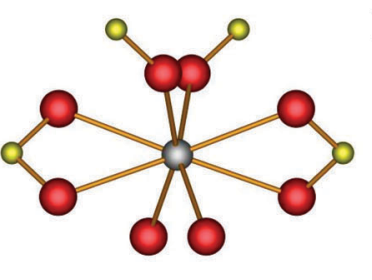

$\mathrm{k}$

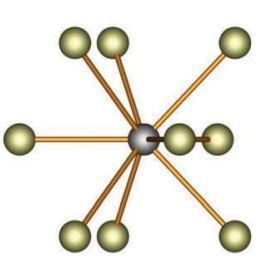

d

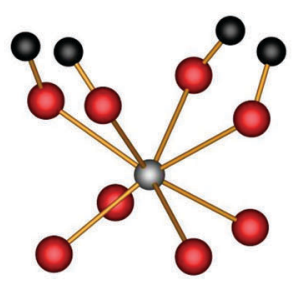

h

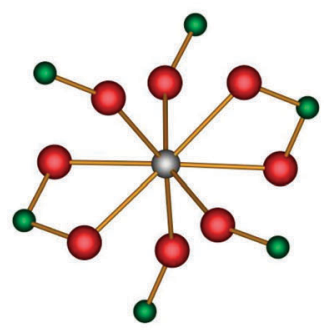

1

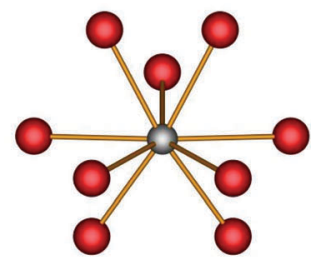

Fig. 1 Local calcium environments for systems with known crystal structures. $\mathrm{Ca}(\mathrm{OH})_{2}$ (a); $\alpha$-calcium formate (b); $\mathrm{CaCl} 2 \cdot 2 \mathrm{H}_{2} \mathrm{O}(\mathrm{c}) ;( \pm)$-calcium tartrate tetrahydrate (d); calcium acetate monohydrate, site 1 (e); calcium acetate monohydrate, site 2 (f); $\mathrm{CaSO}_{4} \cdot 2 \mathrm{H}_{2} \mathrm{O}(\mathrm{g}) ; \mathrm{CaCrO}_{4}(\mathrm{~h}) ; \mathrm{CaTiO}_{3}$ (i); $\mathrm{Ca}\left(\mathrm{NO}_{3}\right)_{2}$ (j); $\mathrm{CaH}_{2}(\mathrm{k})$; aragonite (l). Hydrogen atoms have generally been omitted (except $\mathrm{CaH}_{2}$ ) and only the most local structure about the calcium is shown. The atomic colour scheme is as follows: Ca (silver); O (red); C (black); Cl (light green); S (yellow); Cr (dark green); Ti (aqua); N (blue); H (gold). 
with Materials Studio (v. 3.2.0.0), and used ultrasoft pseudopotentials to describe the core electrons. ${ }^{48,50}$ For all calculations, the generalized gradient approximation (GGA) was used, with the exchange-correlation (XC) functional developed by Perdew, Burke, and Ernzerhof (PBE). ${ }^{51,52}$ Crystal structures were taken from a variety of literature sources, as indicated in Table 1 and also in the ESI, $\dagger$ Tables S3 and S4. For certain systems, optimization of the hydrogen positions was carried out prior to NMR property computations (see ESI, $\dagger$ Table S6 for optimized structural parameters), but the unit cell dimensions were not optimized. Additional pertinent computational details (atomic coordinates, $k$-points, basis set energy cutoff, pseudopotential details) can be found in the ESI, $\dagger$ Tables S3 and S4. To determine the computed Euler angles, EFGShield (v. 4.0 with GUI) was used. ${ }^{53}$ For calculations involving unit cell manipulations, these were carried out by a simple isotropic scaling of the unit cell lengths, without any additional modifications or optimizations.

\section{Results and discussion}

Short discussions of the crystal structures and the local calcium environments for each compound studied are provided below (for an overview of selected structural parameters, see Table 1). To establish if clear links exist between these structural elements and measurable calcium SSNMR observables, we initially discuss systems with well-known structures. As the discussion progresses, further points will be made regarding the calcium environment in cases where the local and long-range structures are not known with such confidence. Experimentally measured ${ }^{43} \mathrm{Ca}$ SSNMR parameters are summarized in Table 2. Where crystal structure data exist, the local $\mathrm{Ca}^{2+}$ environments are displayed in Fig. 1.

\section{A. Calcium hydroxide, $\mathrm{Ca}(\mathrm{OH})_{2}$}

The unit cell and heavy atom positions in $\mathrm{Ca}(\mathrm{OH})_{2}$ were established long ago by both X-ray and neutron diffraction techniques, $^{70,71}$ while specification of the hydrogen atomic positions required additional studies. ${ }^{54,72-74}$ The stable ambient condition crystal structure for $\mathrm{Ca}(\mathrm{OH})_{2}$ is consistently observed to belong to the trigonal $P \overline{3} m 1$ space group, with the Ca atoms at $\overline{3} m$ sites. Due to a $C_{3}$ symmetry element passing through the calcium lattice positions (Fig. 1a), the ${ }^{43} \mathrm{Ca}$ EFG tensor must possess axial symmetry (i.e., the asymmetry parameter of the EFG tensor, $\eta_{\mathrm{Q}}$, must equal 0$),{ }^{75}$ which is interestingly in contrast with several earlier ${ }^{43} \mathrm{Ca}$ NMR measurements that report a small, albeit consistently nonzero $\eta_{\mathrm{Q}}\left({ }^{43} \mathrm{Ca}\right)$ value. ${ }^{33,35,76,77}$ Oxygen-17 SSNMR results have also been presented, ${ }^{78,79}$ and while several measurements of the ${ }^{43} \mathrm{Ca}$ EFG tensor in $\mathrm{Ca}(\mathrm{OH})_{2}$ have been conducted, we are not aware of any attempts to completely determine the calcium CSA tensor in this material, which also includes the measurement of the Euler angles relating the CSA and EFG tensor PASs.

A ${ }^{43} \mathrm{Ca}$ MAS NMR experiment at $B_{0}=21.1 \mathrm{~T}$ facilitated the measurement of the relevant EFG tensor parameters, as well as the calcium $\delta_{\text {iso }}$ value (see ESI, $\dagger$ Fig. S1), and largely yielded values consistent with the majority of the literature reports: $\left(C_{\mathrm{Q}}=2.56(0.03) \mathrm{MHz} ; \eta_{\mathrm{Q}}<0.05 ; \delta_{\text {iso }}=70.4(0.6) \mathrm{ppm} ; \mathrm{NMR}\right.$ parameter definitions can be found in the footnotes of Table 2). ${ }^{33,35,76,77}$ For an illustration of Euler angle definitions, see Fig. S2 in the ESI. $\dagger^{69}$ Static ${ }^{43}$ Ca SSNMR experiments were also performed at multiple applied magnetic fields (Fig. 2 and Fig. S3, ESI $\dagger$ ).

Direct detection experiments at $B_{0}=11.75 \mathrm{~T}$, even when using a single channel $10 \mathrm{~mm}$ solenoid probe and 4 days of acquisition time, resulted in a ${ }^{43} \mathrm{Ca}$ SSNMR spectrum which did not have a satisfactory signal-to-noise $(\mathrm{S} / \mathrm{N})$ ratio (Fig. S3, ESI $\dagger$ ),
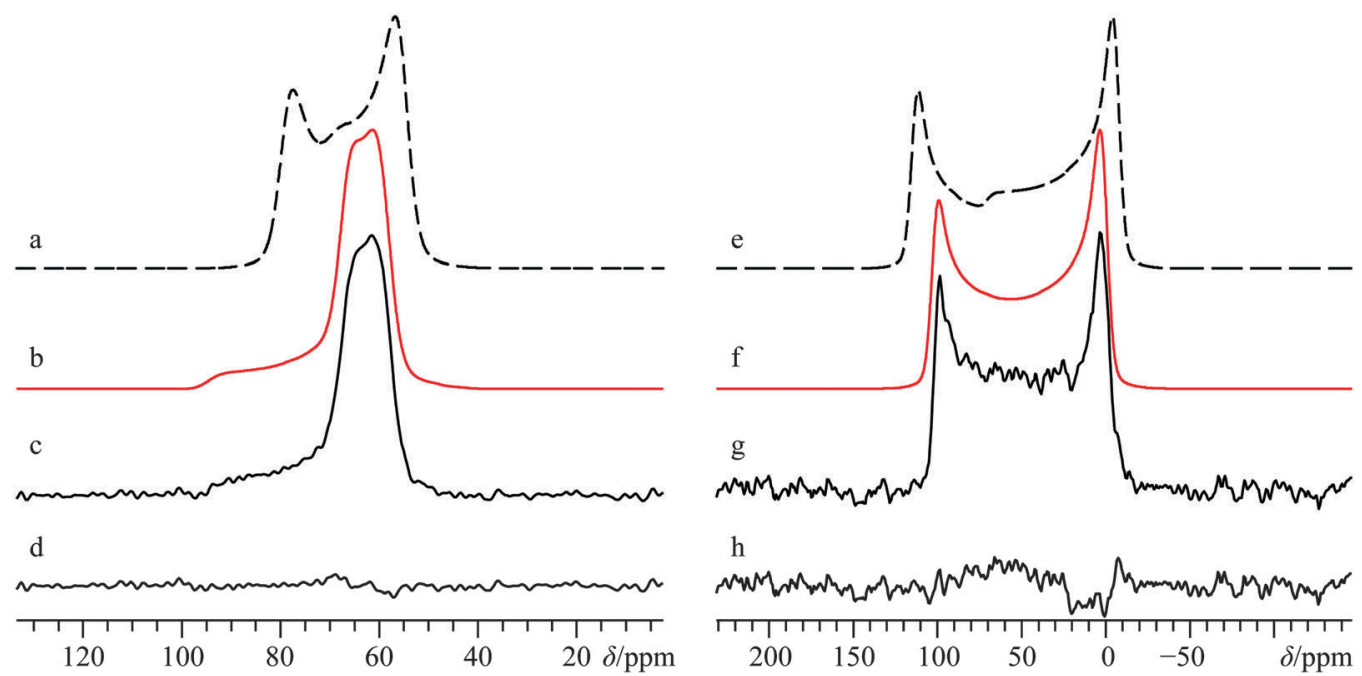

Fig. 2 Analytical line shape simulations (a, b, e, f) and experimental (c, g) ${ }^{43} \mathrm{Ca}\left\{{ }^{1} \mathrm{H}\right\} \mathrm{CP} /$ static SSNMR spectra of $\mathrm{Ca}(\mathrm{OH})_{2}$, acquired at $B_{0}=21.1 \mathrm{~T}(\mathrm{c})$ and $B_{0}=9.4 \mathrm{~T}(\mathrm{~g})$. Traces (b) and (f) represent the best-fit simulations of the experimental spectra, while (a) and (e) ignore calcium CSA by setting $\Omega=0$ ppm. The difference spectrum between (b) and (c) is provided in (d), while the difference spectrum between (f) and (g) is provided in (h). The experimental spectrum in (c) results from the collection of 28200 transients with a recycle delay of $2.0 \mathrm{~s}$ (experiment time $=15.7 \mathrm{~h}$ ), while (g) results from the collection of 273600 transients with a recycle delay of $0.7 \mathrm{~s}$ (experiment time $=53.2 \mathrm{~h}$ ) 
and which was difficult to quantitatively model. Due to the challenging nature of obtaining high quality ${ }^{43} \mathrm{Ca}$ SSNMR spectra under these conditions (i.e., direct polarization at standard applied fields and at natural abundance in ${ }^{43} \mathrm{Ca}$ ), we carried out $\mathrm{CP}$ experiments using ${ }^{1} \mathrm{H}$ nuclei as the polarization source. The CP technique has been applied several times before using samples isotopically enriched in ${ }^{43} \mathrm{Ca} .{ }^{33,38,39}$ Fortunately, the ${ }^{1} \mathrm{H}$ spin-lattice relaxation time (i.e., $\left.T_{1}\right)$ in $\mathrm{Ca}(\mathrm{OH})_{2}$ is rather short, and the CP experiment clearly afforded phenomenal gains in sensitivity relative to direct excitation of ${ }^{43} \mathrm{Ca}$ (contrast Fig. $2 \mathrm{~g}$ with Fig. S3, ESI $\dagger$ ). The Hartmann-Hahn matching condition for half-integer quadrupolar nuclei described earlier (i.e., the nutation frequency of ${ }^{1} \mathrm{H}=(I+1 / 2)=4$ times the nutation frequency of the quadrupolar nucleus $)^{41}$ was confirmed to be optimal for $\mathrm{Ca}(\mathrm{OH})_{2}$ at 21.1 T. Other matching conditions near the optimal value gave rise to significant polarization transfer (Fig. S4, ESI $\dagger$ ), but were not as broad-banded (i.e., non-uniform enhancement across the powder pattern). We also performed optimizations of the CP contact time, finding that approximately $20 \mathrm{~ms}$ was optimal in this case (Fig. 3), which is roughly in accord with prior cases when $\mathrm{CP}$ has been used on ${ }^{43} \mathrm{Ca}$-enriched samples. ${ }^{38}$ The inclusion of phase-modulated ${ }^{1} \mathrm{H}$ decoupling during the acquisition period (Fig. S5, ESI $\dagger$ ) was explored, and while a slight variation in the observed signal was noted, the overall line shape distortion by ${ }^{1} \mathrm{H}^{-43} \mathrm{Ca}$ through-space dipolar coupling is clearly minor, as postulated earlier, ${ }^{20}$ but never experimentally confirmed beforehand for $\mathrm{Ca}(\mathrm{OH})_{2}$.

The CP NMR spectrum in Fig. $2 \mathrm{~g}$ was acquired at $B_{0}=9.4 \mathrm{~T}$ using a $7 \mathrm{~mm}$ solenoid coil (contrast with the ${ }^{43} \mathrm{Ca}$ NMR spectrum acquired at $B_{0}=11.75 \mathrm{~T}$ using a $10 \mathrm{~mm}$ solenoid coil, Fig. S3, ESI $\dagger$ ). To the best of our knowledge, the spectrum in Fig. $2 \mathrm{~g}$

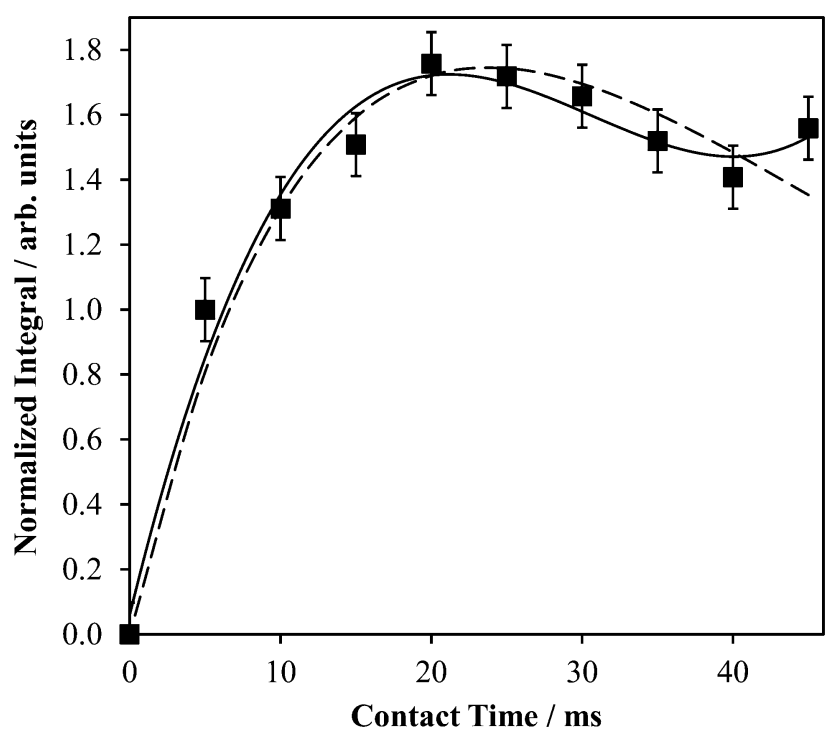

Fig. 3 Experimental ${ }^{1} \mathrm{H} \rightarrow{ }^{43} \mathrm{Ca} \mathrm{CP}$ build-up curve for powdered $\mathrm{Ca}(\mathrm{OH})_{2}$ at $B_{0}=9.4 \mathrm{~T}$. The data were fit to a polynomial expression (solid line): $S=7.977 \times 10^{-5}\left(\tau_{C P}\right)^{3}-7.278 \times 10^{-3}\left(\tau_{C P}\right)^{2}+0.2001\left(\tau_{C P}\right) ; R^{2}=0.978$, where $S=$ the signal intensity (arbitrary units) and $\tau_{\mathrm{CP}}$ is the $\mathrm{CP}$ contact time (ms), and a damped sinusoidal expression (dashed line): $S=80.98(\sin (2.461 \times$ $\left.\left.10^{-3} \tau_{\mathrm{CP}}\right)\right) \exp \left(-0.04198 \tau_{\mathrm{CP}}\right)$. encompasses a couple of firsts: (i) it is the first CP ${ }^{43}$ Ca SSNMR spectrum acquired under static conditions and at natural abundance; and (ii) it allows for the first measurement of the full calcium chemical shift tensor at a standard applied magnetic field (i.e., $B_{0}<12 \mathrm{~T}$ ). An additional $\mathrm{CP} /$ static ${ }^{43} \mathrm{Ca}\left\{{ }^{1} \mathrm{H}\right\}$ SSNMR spectrum was acquired at $B_{0}=21.1 \mathrm{~T}$. Except for the rather poor quality direct-detect spectrum acquired at $11.75 \mathrm{~T}$, by modeling all the above-mentioned spectra simultaneously, we precisely measured the calcium CSA in $\mathrm{Ca}(\mathrm{OH})_{2}$, including the Euler angle values $\left(\Omega=36.5(2.0) \mathrm{ppm} ; \kappa<-0.8 ; \beta=90(4)^{\circ}\right.$; $\gamma=0(4)^{\circ}$, Table 2). It is rather interesting to see the ${ }^{43} \mathrm{Ca}$ NMR spectrum of $\mathrm{Ca}(\mathrm{OH})_{2}$ acquired at $9.4 \mathrm{~T}$ is dominated by secondorder quadrupolar broadening, while the ${ }^{43} \mathrm{Ca}$ NMR spectrum of the same material acquired at $21.1 \mathrm{~T}$ is significantly affected by CSA. This dramatic example of the field dependencies of quadrupolar broadening and CSA nicely underscores the importance of, when possible, acquiring SSNMR data of halfinteger quadrupolar nuclei in two very distinct applied fields. GIPAW DFT calculations of calcium-43 EFG and magnetic shielding tensors using the crystal structure of $\mathrm{Ca}(\mathrm{OH})_{2}$ (Table 3) established by Desgranges et al. ${ }^{54}$ produced values that are in very good agreement with those experimentally measured (Table 2), including the axial tensor symmetry for both the EFG and shielding tensors. As observed on several occasions for quadrupolar nuclei in the past, the eigenvectors that define the EFG and CS tensor PASs are seen to lie parallel to the unit cell axes (see ESI, $\dagger$ Fig. S6). It is also calculated that the direction of least magnetic shielding (i.e., $\sigma_{11}$ ) is collinear with the direction of the largest EFG (i.e., $\left.V_{33}\right)$.

\section{B. $\alpha$-Calcium formate, $\alpha$-Ca( $\left(\mathrm{CHO}_{2}\right)_{2}$}

The crystal structure of $\alpha$-calcium formate has been determined using both X-ray ${ }^{80}$ and neutron ${ }^{56}$ diffraction measurements: it belongs to the orthorhombic Pcab space group. In contrast with $\mathrm{Ca}(\mathrm{OH})_{2}$, the local $\mathrm{Ca}^{2+}$ coordination sphere is populated by seven oxygen atoms (Fig. 1b), and there is a distribution of $\mathrm{Ca}-\mathrm{O}$ bond lengths. The $\alpha$ polymorph has been studied several times using solid-state ${ }^{1} \mathrm{H},{ }^{81}{ }^{2} \mathrm{H},{ }^{82}{ }^{13} \mathrm{C},{ }^{83-87}$ and ${ }^{43} \mathrm{Ca} \mathrm{SSNMR} .{ }^{36}$ While the ${ }^{43} \mathrm{Ca}$ EFG tensor parameters and the calcium $\delta_{\text {iso }}$ value are well-documented, we are not aware of measurements of the calcium CSA for this compound. Carbon-13 SSNMR experiments and ${ }^{43} \mathrm{Ca}$ MAS NMR experiments reproduced prior literature values and confirmed the sample purity $\left({ }^{13} \mathrm{C} \mathrm{CP} / \mathrm{MAS}\right.$ and ${ }^{43}$ Ca MAS NMR spectra can be found in the ESI, $\dagger$ Fig. S7 and $\mathrm{S} 8$, respectively). While ${ }^{1} \mathrm{H} \rightarrow{ }^{43} \mathrm{Ca} \mathrm{CP}$ experiments were attempted on this material, the relatively long proton $T_{1}$ value $(>10 \mathrm{~s})$ made these types of experiments only moderately useful at high field. Static direct detection and CP experiments were attempted at standard applied fields of 9.4 and $11.75 \mathrm{~T}$, but did not provide satisfactory results due to: (i) poor $\mathrm{S} / \mathrm{N}$ even after several days of signal averaging for direct detection, or (ii) difficulties in optimizing the CP matching conditions due to the relatively long proton $T_{1}$. The limited success of CP from ${ }^{1} \mathrm{H}$ nuclei was also noted in an earlier study by Smith and co-workers when studying labeled hydroxyapatite. ${ }^{39}$ It appears that the amazing $\mathrm{CP}$ enhancement obtained for $\mathrm{Ca}(\mathrm{OH})_{2}$ may 
Table 3 GIPAW DFT computed ${ }^{43}$ Ca EFG and chemical shift tensor parameters for various calcium-containing systems ${ }^{a}$

\begin{tabular}{|c|c|c|c|c|c|c|c|}
\hline Compound & $\left|C_{\mathrm{Q}}\left({ }^{43} \mathrm{Ca}\right)\right| / \mathrm{MHz}$ & $\eta_{\mathrm{Q}}$ & $\delta_{\text {iso }}^{b} / \mathrm{ppm}$ & $\Omega / \mathrm{ppm}$ & $\kappa$ & $\alpha, \beta, \gamma /^{\circ}$ & Notes \\
\hline$\alpha$-Calcium formate & 1.41 & 0.899 & 14.1 & 29.6 & -0.190 & $97.7,74.9,251.1$ & This study \\
\hline$\beta$-Calcium formate & 2.86 & 0.342 & -1.6 & 40.8 & 0.094 & $270.0,65.3,0.0$ & This study \\
\hline$(+)$-Calcium tartrate $4 \mathrm{H}_{2} \mathrm{O}$ & 1.14 & 0.628 & 5.4 & 30.0 & -0.205 & $121.4,75.2,298.7$ & This study \\
\hline$( \pm)$-Calcium tartrate $4 \mathrm{H}_{2} \mathrm{O}$ & 0.99 & 0.713 & 4.4 & 17.0 & 0.497 & $245.8,67.9,62.6$ & This study \\
\hline Calcium acetate $\cdot \mathrm{H}_{2} \mathrm{O}(1984)^{c}$ & 1.92 & 0.366 & -7.0 & 38.7 & -0.666 & $280.1,87.2,345.2$ & This study, site 1 \\
\hline $\mathrm{CaCl}_{2} \cdot 2 \mathrm{H}_{2} \mathrm{O}^{d}$ & 3.34 & 0.187 & 63.6 & 25.5 & 0.296 & $180.0,84.6,180.0$ & This study \\
\hline $\mathrm{CaCl}_{2} \cdot 6 \mathrm{H}_{2} \mathrm{O}$ & 0.32 & 0.000 & -27.3 & 9.2 & -0.999 & $29.8,90.0,178.7$ & Widdifield/Bryce ${ }^{66}$ \\
\hline $\mathrm{CaCO}_{3}$, calcite ${ }^{e}$ & 1.47 & 0.00 & 22.7 & 10.8 & 1.00 & $0.0^{f^{\prime}}, 0.0,0.0^{f}$ & Bryce et al. ${ }^{67}$ \\
\hline $\mathrm{CaCO}_{3}$, aragonite ${ }^{e}$ & 0.32 & 0.58 & -27.1 & 52.2 & 0.49 & $0.0,15.0,90.0$ & Bryce et $a l^{67}$ \\
\hline $\mathrm{CaSO}_{4} \cdot 2 \mathrm{H}_{2} \mathrm{O}$ & 1.45 & 0.999 & -19.8 & 57.6 & -0.441 & $270.0,89.7,180.0$ & This study \\
\hline $\mathrm{CaCrO}_{4}$ & 1.35 & 0.000 & -62.7 & 85.8 & -1.000 & $90.0^{f^{\prime}}, 90.0,180.0$ & This study \\
\hline $\mathrm{CaTiO}_{3}$ & 1.97 & 0.683 & 19.3 & 69.6 & 0.420 & $90.0,3.4,0.0$ & This study \\
\hline
\end{tabular}

${ }^{a}$ For a more complete disclosure of the computed EFG and magnetic shielding tensor eigenvalues, see Table S5 (ESI). ${ }^{b}$ Generated using the mapping from magnetic shielding to chemical shifts denoted by Moudrakovski et al. in ref. 77. ${ }^{c}$ The values here correspond to the polymorph provided in ref. 55. For details on the other polymorph, see the ESI, Table S5. ${ }^{d}$ Calculations are similar to what appeared as supporting information in ref. 66, but differ as the present NMR property calculations employ a more modern calcium pseudopotential, which has been shown to be more accurate relative to the earlier pseudopotential. ${ }^{37}{ }^{e}$ Calculations employed an older calcium pseudopotential. ${ }^{f}$ Parameter has vanishingly small effect on experimental NMR spectrum due to symmetry.

not be a general phenomenon for ${ }^{43} \mathrm{Ca}$ under static conditions, unless other sample preparation precautions are undertaken (such as doping with paramagnetic species, as documented in ${ }^{29} \mathrm{Si}$ SSNMR $) .{ }^{88}$ As the $T_{1}\left({ }^{1} \mathrm{H}\right)$ values of the remaining samples in this study more closely resembled that of $\alpha$-calcium formate rather than $\mathrm{Ca}(\mathrm{OH})_{2}$, additional $\mathrm{CP}$ experiments were not exhaustively pursued.

Due to the precision with which the EFG tensor parameters have been determined previously, and confirmed here, the calcium CSA parameters may be extracted with high confidence from a fit of the static ${ }^{43} \mathrm{Ca}$ SSNMR data acquired at $B_{0}=21.1 \mathrm{~T}$. The significant impact of the CSA on the spectral line shape is underscored by including in Fig. 4 a fit which does not consider calcium CSA (Fig. 4c), and which is clearly inconsistent with the experimental spectrum.

We were also able to experimentally measure the set of calcium Euler angles for this compound (Table 2), and found them to be in reasonably good agreement with the results of GIPAW DFT computations (Table 3), although there is a significant difference between experimental and computed $\gamma$ values. Relative to $\mathrm{Ca}(\mathrm{OH})_{2}$, it is seen that the experimentally measured ${ }^{43} \mathrm{Ca}$ EFG and chemical shift tensor magnitudes are reduced for $\alpha-\mathrm{Ca}\left(\mathrm{CHO}_{2}\right)_{2}$, in accord with the GIPAW DFT computations. We note that prior GIPAW DFT calculations exist for $\alpha$-calcium formate using a slightly different structure, ${ }^{67}$ and although there are subtle differences in the resulting calculated parameters, they are generally in good agreement. It also appears that GIPAW DFT computations of the ${ }^{43} \mathrm{Ca}$ EFG tensor parameters for $\alpha$-calcium formate are in better agreement with the experimental data than when compared to cluster-based methods. ${ }^{89}$

To comment upon the potential applicability of ${ }^{43} \mathrm{Ca}$ NMR experiments in distinguishing polymorphic forms, we also

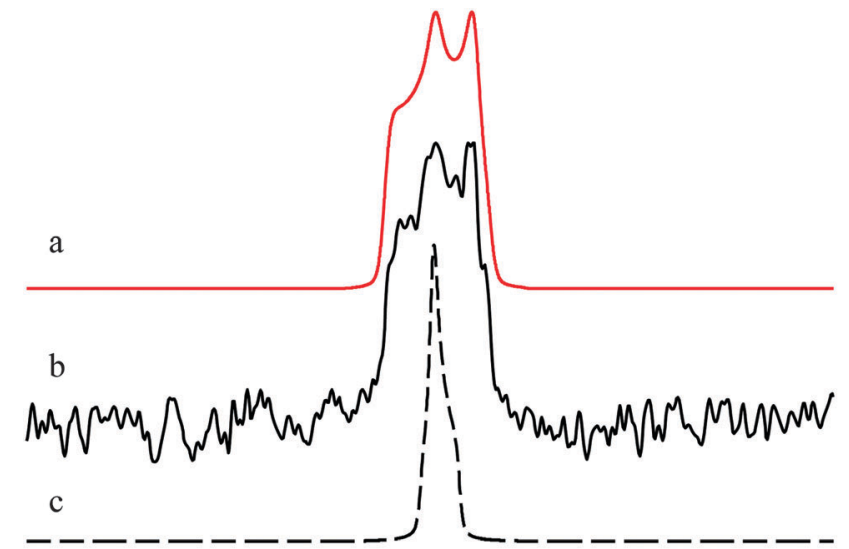

$$
\text { d }
$$

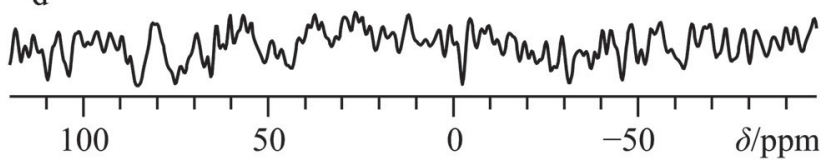

Fig. 4 Analytical line shape simulations $(\mathrm{a}, \mathrm{c})$ and experimental (b) ${ }^{43} \mathrm{Ca}\left\{{ }^{1} \mathrm{H}\right\}$ static SSNMR spectrum of $\alpha-\mathrm{Ca}\left(\mathrm{CHO}_{2}\right)_{2}$, acquired at $B_{0}=21.1 \mathrm{~T}$. Trace (a) represents the best-fit spectrum, while (c) ignores calcium CSA by setting $\Omega=0 \mathrm{ppm}$. The difference spectrum between (b) and (a) is provided in (d). The experimental spectrum in (b) results from the collection of 15952 transients with a recycle delay of $10.0 \mathrm{~s}$ (experiment time $=44.3 \mathrm{~h}$ ).

performed GIPAW DFT computations on the accepted structures of the $\beta$ polymorph of calcium formate. ${ }^{90}$ As we will highlight in this manuscript on several occasions, software using GIPAW DFT is able to accurately calculate both the calcium-43 EFG and magnetic shielding tensors for a variety of calcium-containing materials. The calculated $C_{\mathrm{Q}}\left({ }^{43} \mathrm{Ca}\right)$ value 
for $\beta$-calcium formate is $2.86 \mathrm{MHz}$ (Table 3 ), which is more than double the calculated (and experimentally observed) value for the $\alpha$ polymorph (these values were observed and computed to be $1.25(0.08)$ and $1.41 \mathrm{MHz})$. In addition, the calcium chemical shift value for the $\beta$ polymorph is predicted to be roughly 15 ppm lower relative to the $\alpha$ polymorph. Both of these differences should be easily observable at natural abundance and add further support to the potential utility that ${ }^{43} \mathrm{Ca}$ SSNMR experiments may have in distinguishing polymorphs.

\section{Calcium chloride dihydrate, $\mathrm{CaCl}_{2} \cdot 2 \mathrm{H}_{2} \mathrm{O}$, and pseudopolymorphs thereof}

As part of an earlier study, ${ }^{66}$ we focused on the utility of ${ }^{35 / 37} \mathrm{Cl}$ SSNMR experiments in distinguishing anhydrous and hydrated calcium chloride pseudopolymorphs. It was found that ${ }^{35 / 37} \mathrm{Cl}$ SSNMR parameters were able to differentiate between various stable calcium chloride hydrates, and it was predicted that if ${ }^{43} \mathrm{Ca}$ SSNMR measurements could be performed on $\mathrm{CaCl}_{2} \cdot 2 \mathrm{H}_{2} \mathrm{O}$, they would produce calcium NMR tensor parameters that were unique compared to both $\mathrm{CaCl}_{2}$ and $\mathrm{CaCl}_{2} \cdot 6 \mathrm{H}_{2} \mathrm{O}$. To validate the computational prediction, we carried out ${ }^{43} \mathrm{Ca}$ SSNMR experiments using the same sample employed in a prior chlorine NMR study of $\mathrm{CaCl}_{2} \cdot 2 \mathrm{H}_{2} \mathrm{O}$. ${ }^{91}$

The crystal structure of $\mathrm{CaCl}_{2} \cdot 2 \mathrm{H}_{2} \mathrm{O}$ determined using XRD methods ${ }^{58}$ belongs to the orthorhombic $\mathrm{Pbcn}$ space group, with the $\mathrm{Ca}^{2+}$ ions located on $C_{2}$ sites (Fig. 1c). Prior ${ }^{2} \mathrm{H}$ SSNMR experiments on various deuterated hydrates of $\mathrm{CaCl}_{2}$ have explored the various modes of water dynamics which occur in this class of systems. ${ }^{92}$ Presently, MAS experiments at $B_{0}=21.1 \mathrm{~T}$ clearly identify a single calcium environment whose ${ }^{43} \mathrm{Ca}$ NMR line shape is broadened by the second-order QI (Fig. 5b). A satisfactory fit to the experimental signal is arrived at using $C_{\mathrm{Q}}\left({ }^{43} \mathrm{Ca}\right)=2.62(0.06) \mathrm{MHz}$, $\eta_{\mathrm{Q}}=0.22(0.05)$, and $\delta_{\text {iso }}=51.2(0.4) \mathrm{ppm}$. Subsequent static NMR experiments on this sample highlight a relatively modest calcium CSA $(\Omega=19(5)$ ppm, Fig. $5 f)$.
Based on the $C_{2}$ site symmetry at the $\mathrm{Ca}$, the parameter space for the $\alpha$ and $\gamma$ Euler angles can be restricted significantly. This is supported by GIPAW DFT computations, and we establish that the largest components of the EFG and calcium shift tensors are non-coincident (i.e., $\beta \neq 0^{\circ}$ ). Importantly, we note the critical role that the $\beta$ value plays in the observed ${ }^{43} \mathrm{Ca}$ NMR signal for this system, as outlined in Fig. 5. We also note that high field NMR experiments were essential to acquire spectra with a reasonable $\mathrm{S} / \mathrm{N}$ ratio for $\mathrm{CaCl}_{2} \cdot 2 \mathrm{H}_{2} \mathrm{O}$, as ${ }^{43} \mathrm{Ca} \mathrm{NMR}$ experiments at $B_{0}=11.75 \mathrm{~T}$ using a $10 \mathrm{~mm}$ coil gave barely any noticeable signal, even after nearly three days of signal averaging (Fig. S9, ESI $\dagger$ ).

In full accord with the GIPAW DFT calculations presented in the earlier study, ${ }^{66}$ the observed ${ }^{43} \mathrm{Ca}$ SSNMR spectra and corresponding EFG and CS tensor parameters for $\mathrm{CaCl}_{2} \cdot 2 \mathrm{H}_{2} \mathrm{O}$ are clearly distinct from the anhydrous and hexahydrate forms of $\mathrm{CaCl}_{2}$. It is seen that the experimental $\left|C_{\mathrm{Q}}\left({ }^{43} \mathrm{Ca}\right)\right|$ value for $\mathrm{CaCl}_{2} \cdot 2 \mathrm{H}_{2} \mathrm{O}$ is somewhat less than the calculated value (Table 3), and postulate that the known fast (10 to $100 \mathrm{ps)} \mathrm{motions} \mathrm{of} \mathrm{the}$ water molecules $^{92}$ are likely partially averaging the EFG at the calcium nuclei. Nevertheless, the present finding further highlights the potential utility of ${ }^{43} \mathrm{Ca}$ SSNMR experiments when distinguishing pseudopolymorphs. We also note that GIPAW DFT calculations of the relevant NMR tensor parameters for the known (but unstable) polymorphs of $\mathrm{CaCl}_{2} \cdot 4 \mathrm{H}_{2} \mathrm{O}$ (i.e., the $\alpha, \beta$, and $\gamma$ polymorphs, as in ref. 66) predict that ${ }^{43} \mathrm{Ca}$ SSNMR experiments would very likely be able to distinguish these systems (i) from the three forms of $\mathrm{CaCl}_{2}$ described directly above, and (ii) from one another.

\section{Racemic calcium tartrate tetrahydrate, $( \pm)-\mathrm{Ca}\left(\mathrm{C}_{4} \mathrm{H}_{4} \mathrm{O}_{6}\right) \cdot 4 \mathrm{H}_{2} \mathrm{O}$}

As commonly observed in the wine industry, calcium tartrate is naturally present as an enantiomerically pure tetrahydrate (i.e., (+)-Ca( $\left.\left(\mathrm{L}-\mathrm{C}_{4} \mathrm{H}_{4} \mathrm{O}_{6}\right) \cdot 4 \mathrm{H}_{2} \mathrm{O}\right),{ }^{93}$ although other hydrated forms

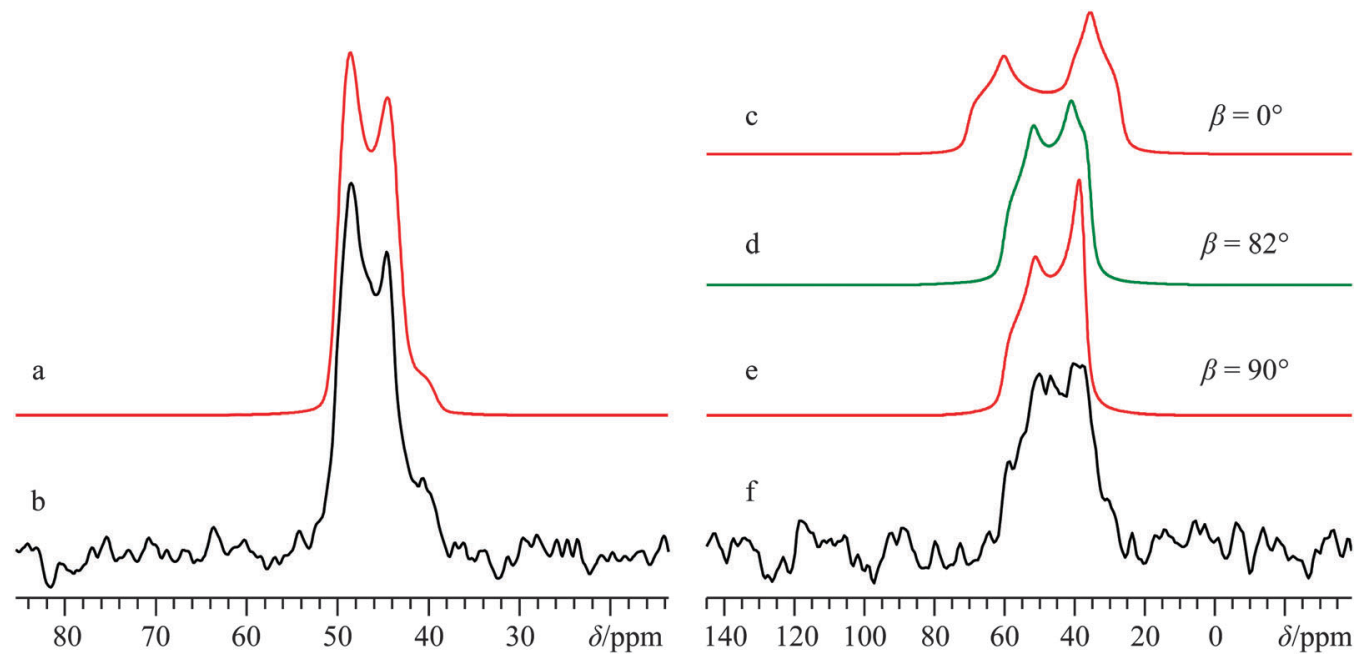

Fig. 5 Analytical line shape simulations (a, c-e), experimental ${ }^{43} \mathrm{Ca}$ SSNMR spectrum under MAS $\left(\nu_{\mathrm{MAS}}=4.5 \mathrm{kHz}, \mathrm{b}\right)$, and ${ }^{43} \mathrm{Ca}\left\{{ }^{1} \mathrm{H}\right\} \mathrm{SSNMR}$ spectrum under static conditions (f) of $\mathrm{CaCl}_{2} \cdot 2 \mathrm{H}_{2} \mathrm{O}$, acquired at $B_{0}=21.1 \mathrm{~T}$. The experimental spectrum in (b) results from the collection of 7920 transients with a recycle delay of $10.0 \mathrm{~s}$ (experiment time $=22.0 \mathrm{~h}$ ), while the spectrum in (f) resulted from collecting 7220 transients with a recycle delay of $10.0 \mathrm{~s}$ (experiment time $=20.1 \mathrm{~h}$ ). The pronounced sensitivity of the simulated static line shapes with respect to variation in $\beta$ is highlighted in (c-e), with selected $\beta$ values indicated to the right of the simulated line shapes. 
can be prepared. ${ }^{94}$ A number of prior XRD measurements ${ }^{95-97}$ have been carried out on the enantio-pure form, although recently a crystal structure for the racemic form of calcium tetrahydrate has been determined via Rietveld refinements. ${ }^{57}$ Due to the lack of point symmetry at the calcium (Fig. 1d), the corresponding EFG and CS tensor parameters can take any value, making data fitting more complicated in comparison to the three systems discussed above. Due to the reasonably high degree of correlation between the experimental and computed calcium NMR tensor parameters for the systems studied herein (vide infra), we relied on a complementary approach which uses both experimental NMR measurements and GIPAW DFT computed values to determine the calcium NMR tensor parameters.

To the best of our knowledge, $( \pm)-\mathrm{Ca}\left(\mathrm{C}_{4} \mathrm{H}_{4} \mathrm{O}_{6}\right) \cdot 4 \mathrm{H}_{2} \mathrm{O}$ has never been studied via ${ }^{43} \mathrm{Ca}$ SSNMR. As such, we employed ${ }^{13} \mathrm{C}$ SSNMR and pXRD measurements to verify sample purity (see Fig. S10 and S11 of the ESI $\dagger$ ). No presence of the starting material (DL-tartaric acid) was observed, and small changes in the ${ }^{13} \mathrm{C}$ chemical shifts of the tartrate anion were observed, which are consistent with product formation. The ${ }^{43} \mathrm{Ca}$ MAS SSNMR signal recorded at $B_{0}=21.1 \mathrm{~T}$ (Fig. $6 \mathrm{~b}$ ) is rather narrow and quite shielded $\left(\delta_{\text {iso }}=-0.5(0.5) \mathrm{ppm}\right)$.

According to the established relationship between $\delta_{\text {iso }}\left({ }^{43} \mathrm{Ca}\right)$ and coordination number, ${ }^{19,20}$ the observed calcium chemical shift is consistent with a calcium coordination number of 8 , as observed in the known crystal structure. With such a high coordination number about the only unique calcium in the crystal structure, it is not surprising that $\left|C_{\mathrm{Q}}\right|$ is rather small: $C_{\mathrm{Q}}<1.2 \mathrm{MHz} ; \eta_{\mathrm{Q}}=0.6(0.1)$.

With such a small $C_{\mathrm{Q}}$ value, ${ }^{43} \mathrm{Ca}$ NMR experiments conducted on a stationary sample at $21.1 \mathrm{~T}$ will give a signal that is broadened predominantly by CSA. Line shape modeling of the static ${ }^{43} \mathrm{Ca}\left\{{ }^{1} \mathrm{H}\right\}$ SSNMR spectrum presented in Fig. 6d (and detailed further in Fig. S12, ESI $\dagger$ ), yields values of $\Omega=23(3)$ ppm and $\kappa=0.1(0.2)$ and also establish that the EFG and magnetic shielding tensors are not coincident in this system.
Tensor non-coincidence is consistent with the calcium site symmetry for this compound, and agrees with the GIPAW DFT computations for this material (Table 3). We also note that GIPAW DFT calculations predict that there is a substantial calcium chemical shift difference ( $c a .20 \mathrm{ppm}$ ) between the tetrahydrate and trihydrate forms, based on the accepted structures of all forms. ${ }^{57,94,97}$ The $C_{\mathrm{Q}}\left({ }^{43} \mathrm{Ca}\right)$ value for the trihydrate is also predicted to be significantly larger than either tetrahydrate (Table 3 ). This again highlights the potential of ${ }^{43} \mathrm{Ca}$ SSNMR for distinguishing between hydrated forms of calcium-containing materials.

\section{E. Enriched calcium acetate monohydrate, ${ }^{43} \mathrm{Ca}\left(\mathrm{C}_{2} \mathrm{H}_{3} \mathrm{O}_{2}\right)_{2}$. $\mathrm{H}_{2} \mathrm{O}$}

A crystal structure of calcium acetate monohydrate is known for at least two polymorphs, ${ }^{55,98}$ where the form obtained can be controlled through the preparation method. A hemi-hydrated version may also be generated by performing the crystallization at temperatures greater than $60{ }^{\circ} \mathrm{C} .{ }^{99,100}$ Spek and co-workers reported the structure of one polymorphic form of $\mathrm{Ca}\left(\mathrm{C}_{2} \mathrm{H}_{3} \mathrm{O}_{2}\right)_{2}$. $\mathrm{H}_{2} \mathrm{O}$ in $1984 .{ }^{55}$ They found the space group to be $P \overline{1}$ with two inequivalent calcium atoms, each lying on a general lattice position (see Fig. 1e and for the local calcium environments). A second polymorph of $\mathrm{Ca}\left(\mathrm{C}_{2} \mathrm{H}_{3} \mathrm{O}_{2}\right)_{2} \cdot \mathrm{H}_{2} \mathrm{O}$ was presented by the same research group in 1987 and bears much in common with the 1984 polymorph (i.e., $P \overline{1}$, two non-equivalent $\mathrm{Ca}^{2+}$ ions on general positions). ${ }^{98}$ The most significant distinction between the two polymorphs from the perspective of the calcium is that both unique water molecules coordinate to the calcium in the 1984 polymorph, while only one coordinates in the 1987 polymorph. Prior ${ }^{43} \mathrm{Ca}$ NMR measurements were carried out on this material, including the famous first example of ${ }^{1} \mathrm{H} \rightarrow{ }^{43} \mathrm{Ca} \mathrm{CP} /$ MAS, which included the complete destruction of the NMR probe due to the very long and high-power contact times involved. $^{38}$
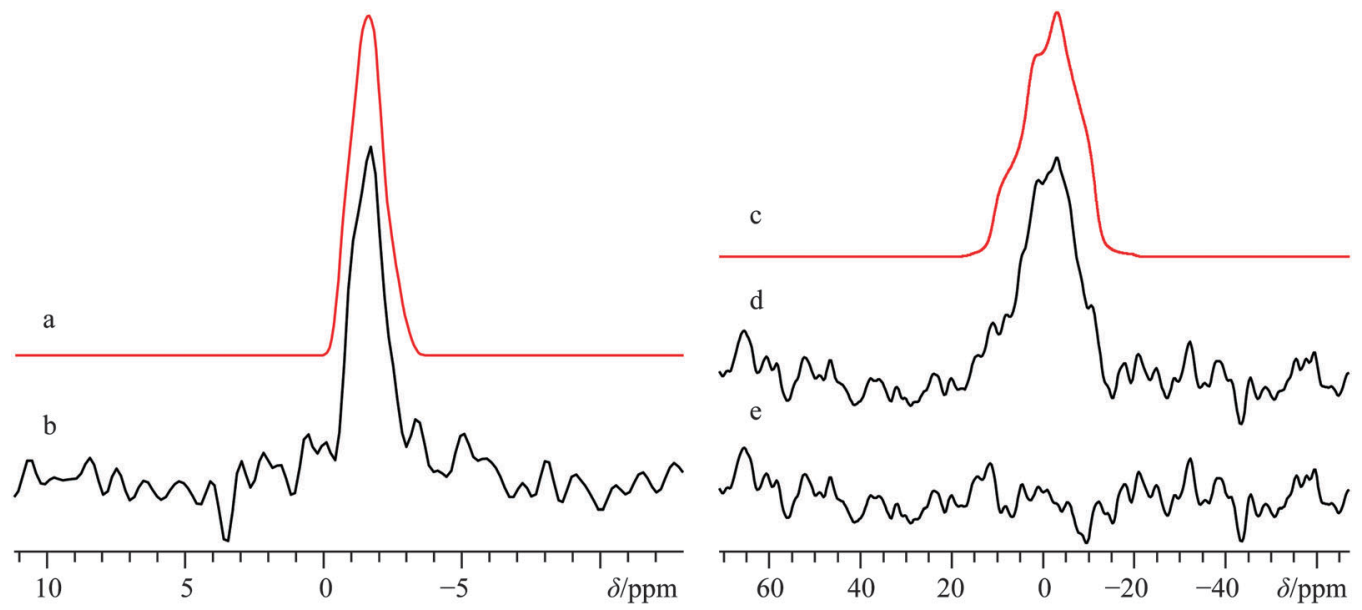

Fig. 6 Analytical line shape simulations $(\mathrm{a}, \mathrm{c})$ and experimental ${ }^{43} \mathrm{Ca}$ SSNMR spectrum of $( \pm)-\mathrm{Ca}\left(\mathrm{C}_{4} \mathrm{H}_{4} \mathrm{O}_{6}\right) \cdot 4 \mathrm{H}_{2} \mathrm{O}$ under MAS $\left(\nu_{\text {MAS }}=5.0 \mathrm{kHz}\right.$, b), and ${ }^{43} \mathrm{Ca}\left\{{ }^{1} \mathrm{H}\right\}$ SSNMR spectrum under static conditions (d), both acquired at $B_{0}=21.1 \mathrm{~T}$. The difference spectrum between (c) and (d) is provided in (e). The experimental spectrum in (b) results from the collection of 4896 transients with a recycle delay of $7.0 \mathrm{~s}$ (experiment time $=9.5 \mathrm{~h}$ ), while the spectrum in (d) resulted from collecting 24000 transients with a recycle delay of $10.0 \mathrm{~s}$ (experiment time $=66.7 \mathrm{~h}$ ). 

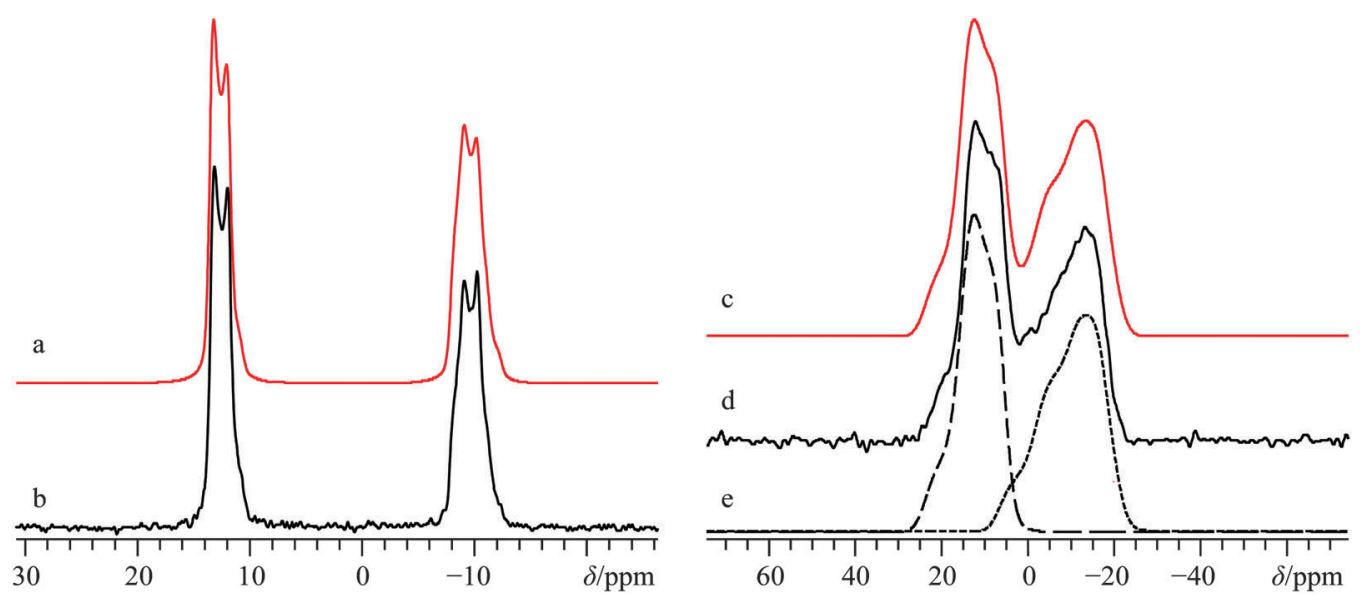

Fig. 7 Analytical line shape simulations (a, c, e), experimental (b, d) ${ }^{43} \mathrm{Ca}$ MAS $\left(\nu_{\text {MAS }}=5.0 \mathrm{kHz}, \mathrm{b}\right)$ and static ${ }^{43} \mathrm{Ca}\left\{{ }^{1} \mathrm{H}\right\}$ (d) SSNMR spectra of ${ }^{43} \mathrm{Ca}\left(\mathrm{C}_{2} \mathrm{H}_{3} \mathrm{O}_{2}\right){ }_{2}$. $\mathrm{H}_{2} \mathrm{O}$, enriched to ca. $7 \%$ in ${ }^{43} \mathrm{Ca}$, and acquired at $B_{0}=21.1 \mathrm{~T}$. The experimental spectra result from the collection of 64 transients with a recycle delay of $5.0 \mathrm{~s}$ (experiment time $=5.3 \mathrm{~min}$ ) for (b), and from 256 transients with a recycle delay of $30.0 \mathrm{~s}$ (experiment time $=2.1 \mathrm{~h}$ ) for (d). In (e), a deconvolution of the two calcium sites is provided.

Presently, ${ }^{43} \mathrm{Ca}$ MAS SSNMR spectra at $B_{0}=9.4 \mathrm{~T}$ and $21.1 \mathrm{~T}$ were used to very precisely measure the isotropic calcium chemical shifts, as well as the ${ }^{43} \mathrm{Ca}$ EFG tensor parameters for both sites (Fig. 7b, Fig. S13b, ESI, † and Table 2) using a sample which was isotopically enriched in ${ }^{43} \mathrm{Ca}(\mathrm{ca}$. 7\%). Although prior measurements of $\delta_{\text {iso }}\left({ }^{43} \mathrm{Ca}\right)$ exist for this system, ${ }^{36}$ we would suggest that the present values are more accurate due to data being collected at multiple applied fields. Interestingly, there is a rather large difference in the two observed calcium $\delta_{\text {iso }}$ values for this system of over $20 \mathrm{ppm}$. Additional ${ }^{43} \mathrm{Ca}$ SSNMR experiments under static conditions at $B_{0}=9.4$ and $21.1 \mathrm{~T}$ (Fig. $7 \mathrm{~d}$ and Fig. S13d, ESI $\dagger$ ) allow for the precise measurement of CSA for both overlapping sites, including Euler angle values.

By coupling our ${ }^{43} \mathrm{Ca}$ NMR results with complementary ${ }^{13} \mathrm{C}$ SSNMR and pXRD results (see Fig. S14 and S15, ESI $\dagger$ for ${ }^{13} \mathrm{C}$ SSNMR and pXRD results, respectively) we confirm that the sample used here corresponds to the monohydrated polymorph outlined by Spek and co-workers in 1984. It is immediately clear that the GIPAW DFT-computed NMR tensor parameters are in very good agreement with the experimentally measured values (Table 3), and the observed ${ }^{43} \mathrm{Ca}$ SSNMR powder patterns may thus be confidently assigned to sites in the crystal lattice. GIPAW DFT calculations of the same NMR tensor parameters using the other known polymorph of calcium acetate monohydrate are in relatively poor agreement (Table S5). We note that the computed ${ }^{13} \mathrm{C}$ chemical shift values for the acetate ligands are also in rather good agreement with the experimentally observed values.

\section{F. Calcium levulinate dihydrate, $\mathrm{Ca}\left(\mathrm{C}_{5} \mathrm{H}_{7} \mathrm{O}_{3}\right)_{2} \cdot 2 \mathrm{H}_{2} \mathrm{O}$}

While calcium levulinate dihydrate does not possess a known crystal structure, based upon prior studies using ${ }^{43} \mathrm{Ca}$ SSNMR, as well as the results outlined in the systems directly above, it was thought that it would be possible to obtain important structural information by performing ${ }^{43} \mathrm{Ca}$ SSNMR experiments on this compound. As with calcium tartrate tetrahydrate,
${ }^{13} \mathrm{C}$ NMR experiments on calcium levulinate dihydrate confirmed sample purity via the anionic ligand. As such, the ${ }^{13} \mathrm{C}$ NMR results are fully consistent with the presence of a single crystallographically distinct levulinate anion (Fig. S16, ESI $\dagger$ ). Based on these combined NMR results (vide infra for ${ }^{43} \mathrm{Ca}$ ), it appears reasonably likely that $Z^{\prime}=1$, a finding which may be of use in future attempts to determine the crystal structure of this compound.

A ${ }^{43} \mathrm{Ca}$ MAS NMR spectrum for this material is provided in Fig. 8, and at first glance appears rather similar to what was observed for the tartrate system. When considered in tandem, the small ${ }^{43} \mathrm{Ca} C_{\mathrm{Q}}$ value of $1.3(0.1) \mathrm{MHz}$ and the very shielded calcium chemical shift of $-4.5(1.0) \mathrm{ppm}$ are consistent with a

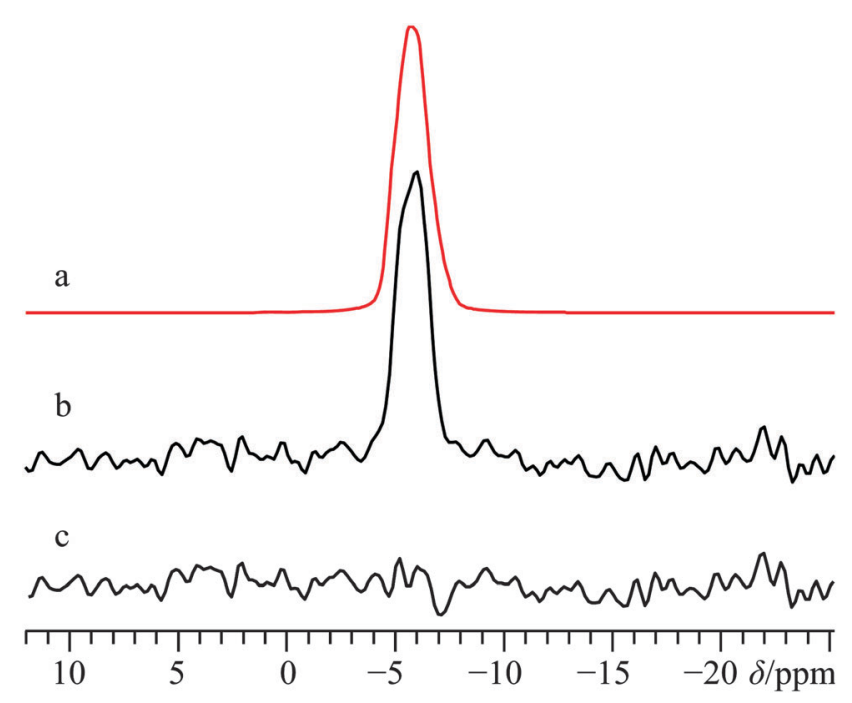

Fig. 8 Analytical line shape simulation (a) and experimental ${ }^{43} \mathrm{Ca}$ SSNMR spectrum of calcium levulinate dihydrate under MAS $\left(\nu_{\text {MAS }}=4.5 \mathrm{kHz}\right),(b)$, acquired at $B_{0}=21.1 \mathrm{~T}$. The difference spectrum between (a) and (b) is provided in (c). The experimental spectrum in (b) results from the collection of 8495 transients with a recycle delay of $10.0 \mathrm{~s}$ (experiment time $=$ $23.6 \mathrm{~h})$. 
high coordination number about the calcium cation, likely eight. Although the ${ }^{43} \mathrm{Ca}$ SSNMR line width for calcium levulinate dihydrate is rather similar to the tartrate, due to the relatively bulkier levulinate anion (and hence clearly lower ${ }^{43} \mathrm{Ca}$ content by mass), acquisition of the ${ }^{43}$ Ca MAS NMR spectrum was considerably more time consuming in the present case. While static ${ }^{43} \mathrm{Ca}$ NMR experiments were attempted on this material at $B_{0}=21.1 \mathrm{~T}$, we could not obtain data of high enough quality for data analysis which may have been able to extract calcium CSA.

Thus, while calcium MAS NMR experiments on systems of this size are feasible, we clearly observed that even relatively small amounts of ${ }^{43} \mathrm{Ca}$ dilution renders static ${ }^{43} \mathrm{Ca}$ NMR at natural abundance a very substantial challenge. Signal enhancement techniques, such as RAPT, ${ }^{43,101}$ adiabatic DFS, ${ }^{42}$ and other interesting varieties, ${ }^{102,103}$ could be used for signal enhancement under MAS, but producing undistorted line shapes under static conditions can be somewhat challenging without the most modern spectrometers or extensive optimization. Likewise, due to the relatively narrow line shapes and unfavourable ${ }^{43} \mathrm{Ca} T_{2}$ relaxation properties for several of the samples under study, we did not find much benefit in multiple-echo sensitivity enhancement techniques, such as the quadrupolar Carr-Purcell Meiboom-Gill (QCPMG) experiment. ${ }^{103}$ Due to these considerations, these signal enhancement routes were not explored further.

\section{G. Enriched calcium sulfate dihydrate, ${ }^{43} \mathrm{Ca}^{33} \mathrm{SO}_{4} \cdot 2 \mathrm{H}_{2} \mathrm{O}$}

$\mathrm{CaSO}_{4}$ may be found in several distinct forms, including hydrates. Anhydrous $\beta-\mathrm{CaSO}_{4}$ can be found in nature as the mineral anhydrite ${ }^{104}$ while the anhydrous $\gamma-\mathrm{CaSO}_{4}$ form may be prepared by thermal decomposition of $\mathrm{CaSO}_{4}$ hydrates. ${ }^{105}$ Calcium sulfate hemihydrate, $\mathrm{CaSO}_{4} \cdot 0.5 \mathrm{H}_{2} \mathrm{O}$, also known as plaster of Paris, is occasionally found as the mineral Bassanite, ${ }^{106}$ and can be prepared on an industrial scale by the low temperature decomposition of $\mathrm{CaSO}_{4} \cdot 2 \mathrm{H}_{2} \mathrm{O}$ at about 100 to $120{ }^{\circ} \mathrm{C}$. This last form, $\mathrm{CaSO}_{4} \cdot 2 \mathrm{H}_{2} \mathrm{O}$, is perhaps the most well-known of all calcium sulfates, and is commonly found in mineral deposits as gypsum, and together with the plaster of Paris represents an important industrial and building material. ${ }^{107}$ The dihydrate was also one of the compounds used in Pake's seminal paper dealing with dipolar broadening of ${ }^{1} \mathrm{H}$ NMR absorption lines in solids. ${ }^{108}$
It appears that no ${ }^{43} \mathrm{Ca}$ EFG tensor information exists for $\mathrm{CaSO}_{4} \cdot 2 \mathrm{H}_{2} \mathrm{O}$, as prior accounts ${ }^{34,67}$ report only experimental calcium peak positions. Several X-ray and neutron diffraction experiments have been performed to elucidate the crystal structure of this material, ${ }^{109-111}$ and we note that a recent $\mathrm{X}$-ray crystal structure study places the calcium at lattice positions with 2 -fold rotational symmetry in the space group $C 2 / c .^{60}$ The space group assignment is consistent with the pXRD data acquired as part of this study (see ESI, $\dagger$ Fig. S17). The single unique $\mathrm{Ca}^{2+}$ is coordinated by eight oxygen atoms (Fig. 1g), which suggests a relatively shielded calcium environment, and which is borne out experimentally using a sample enriched to ca. $7 \%{ }^{43} \mathrm{Ca}\left(\delta_{\text {iso }}=-19.1(0.3)\right.$ ppm, Fig. 9b). The measured ${ }^{43} \mathrm{Ca}$ EFG tensor parameters highlight a very symmetric electronic environment which does not possess axial symmetry and hence limits the rotational site symmetry to two-fold $\left(C_{\mathrm{Q}}\left({ }^{43} \mathrm{Ca}\right)=1.28(0.03)\right.$; $\left.\eta_{\mathrm{Q}}=0.60(0.03)\right)$. The calcium CSA is significantly larger than observed for many of the organic calcium-containing systems $(\Omega=43(2) \mathrm{ppm} ; \kappa=-0.31(0.07))$. As expected by the local Ca site symmetry, the measured Euler angles depict non-coincident tensor frames, but indicate that they share some form of symmetry element. This is consistent with GIPAW DFT calculations on the known crystal structure for this material, (Table 3) although the actual values determined by GIPAW DFT using the structure of Comodi et al. ${ }^{60}$ differ from those experimentally observed. The discrepancy could be remedied by considering the possibility of sulfate librational motions, which can become pronounced in certain situations. ${ }^{112}$ Regardless, all NMR tensor parameters have been determined with high precision, and are fully consistent with MAS and static NMR measurements carried out at $B_{0}=9.4 \mathrm{~T}$ (Fig. S18 of the ESI $\dagger$ ).

\section{H. Calcium chromate, $\mathrm{CaCrO}_{4}$}

Preliminary structural studies of $\mathrm{CaCrO}_{4}$ using XRD were carried out nearly a century ago by Clouse, ${ }^{113,114}$ and relatively recently a slightly modified structure for this material was proposed. ${ }^{61}$ The common form of this material belongs to the tetragonal $I 4_{1}$ /amd space group with the calcium ions at very high symmetry locations ( $\overline{4} m 2$, Fig. $1 \mathrm{~h})$, which is expected to greatly constrain the resulting EFG and CS tensor parameters
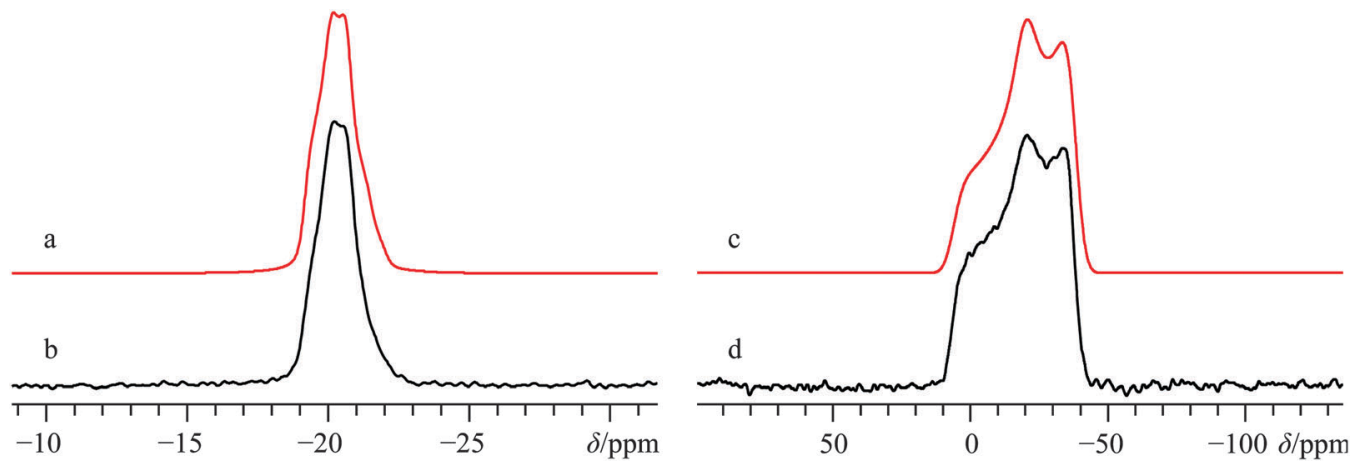

Fig. 9 Analytical line shape simulations (a, c), experimental ${ }^{43} \mathrm{Ca}$ MAS SSNMR spectrum $\left(\nu_{\text {MAS }}=5.0 \mathrm{kHz}\right.$, b), and experimental ${ }^{43} \mathrm{Ca}\left\{{ }^{1} \mathrm{H}\right\}$ static SSNMR spectrum (d) of ${ }^{43} \mathrm{Ca}^{33} \mathrm{SO}_{4} \cdot 2 \mathrm{H}_{2} \mathrm{O}$ (enriched to ca. $7 \%$ in ${ }^{43} \mathrm{Ca}$ ), acquired at $B_{0}=21.1 \mathrm{~T}$. The experimental spectra result from the collection of 32 transients with a recycle delay of $200 \mathrm{~s}$ (experiment time $=1.8 \mathrm{~h}$ for b), and from 112 transients with a recycle delay of $200 \mathrm{~s}$ (experiment time $=6.2 \mathrm{~h}$ for $\mathrm{d}$ ). 


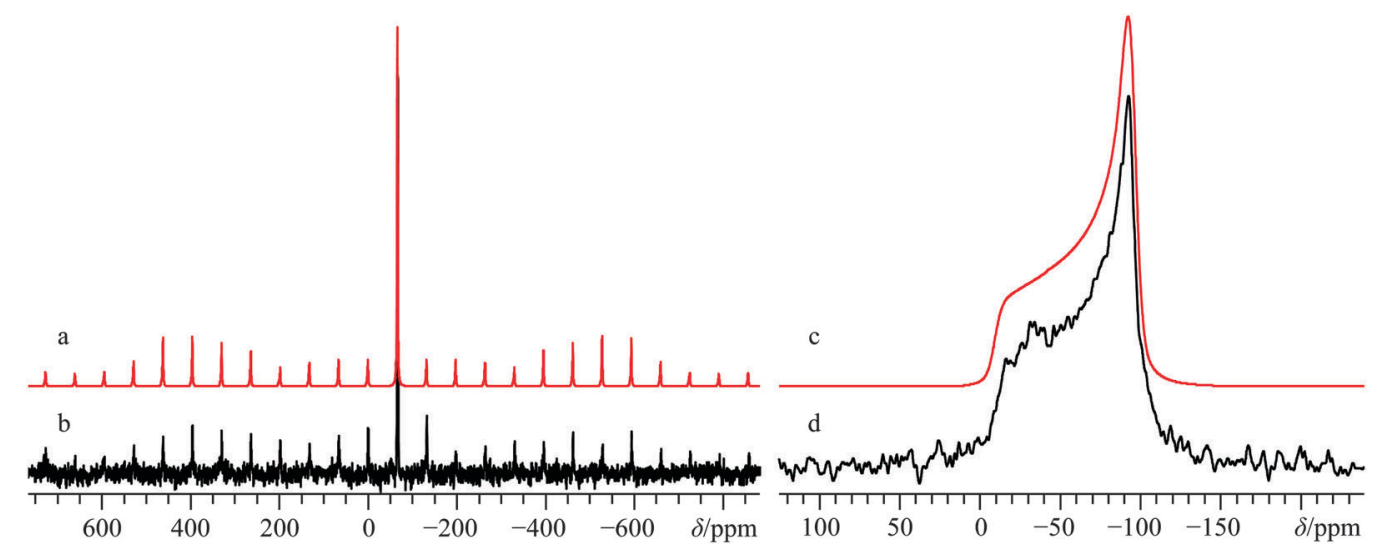

Fig. 10 Numerical line shape simulation (a), analytical line shape simulation (c), experimental ${ }^{43} \mathrm{Ca}$ MAS SSNMR spectrum ( $\nu_{\mathrm{MAS}}=4.0 \mathrm{kHz}$, b), and experimental ${ }^{43} \mathrm{Ca}$ static SSNMR spectrum (d) of $\mathrm{CaCrO}_{4}$, acquired at $B_{0}=21.1 \mathrm{~T}$. The experimental spectra result from the collection of 22722 transients with a recycle delay of $3 \mathrm{~s}$ (experiment time $=18.9 \mathrm{~h}, \mathrm{~b}$ ), and from 37485 transients with a recycle delay of $0.5 \mathrm{~s}$ (experiment time $=5.2 \mathrm{~h}, \mathrm{~d}$ ).

for this system. No prior ${ }^{43} \mathrm{Ca}$ NMR information exists for this material, although ${ }^{53} \mathrm{Cr}$ SSNMR studies have been performed by Forgeron and Wasylishen. ${ }^{115}$ In accord with the known crystal structure (see Fig. S19, ESI $\dagger$ for pXRD diffractogram), we conclude that the ${ }^{43} \mathrm{Ca}$ NMR data acquired at $B_{0}=9.4 \mathrm{~T}$ (Fig. S20, ESI $\dagger$ ) and $21.1 \mathrm{~T}$ (Fig. 10) are consistent with a high local site symmetry, as both tensors are, within measurement error, axially symmetric $\left(\eta_{\mathrm{Q}}<0.1 ; \kappa=-1\right)$. The very small $C_{\mathrm{Q}}$ value $(0.96(0.05) \mathrm{MHz})$ highlights a highly symmetric environment about the calcium. This is very interesting when taken in concert with the very large CS tensor span $(\Omega=87(3) \mathrm{ppm})$, which is the largest calcium $\Omega$ value measured to date. As part of the computational section below, we offer discussion of GIPAW DFT calculations which rationalize this observation. Likewise, the combination of a small $C_{\mathrm{Q}}\left({ }^{43} \mathrm{Ca}\right.$ ) value with a substantial $\Omega$ value, while perhaps unexpected, is not unique for calcium-containing materials, as for example the $C_{\mathrm{Q}}{ }^{43} \mathrm{Ca}$ ) value for the aragonite polymorph of $\mathrm{CaCO}_{3}$ is about $260 \mathrm{kHz},{ }^{67,68}$ while the span value is nearly $50 \mathrm{ppm}$.

The highly shielded calcium environment $\left(\delta_{\text {iso }}=-65.4(0.3)\right.$ $\mathrm{ppm}$ ) is consistent with a high calcium coordination number and short calcium-oxygen bond distances, but is considerably shielded relative to the calcium systems which possess organic anions. This emphasizes that care must be taken when using prior data which correlates calcium $\delta_{\text {iso }}$ with $\mathrm{Ca}-\mathrm{O}$ bond distances. While we further discuss the topic of the calcium CS tensor of $\mathrm{CaCrO}_{4}$ in the computational section, we note that GIPAW DFT computations using an accepted crystal structure ${ }^{61}$ for $\mathrm{CaCrO}_{4}$ provide calculated NMR tensor parameters that are in very good agreement with the experimentally observed values.

\section{Calcium titanate, $\mathrm{CaTiO}_{3}$}

The crystal structure of the ceramic material $\mathrm{CaTiO}_{3}$ belongs to the perovskite structure class, and even today its structure is the focus of active research, more specifically the evolution of the ambient condition structure (orthorhombic Pbnm space group $^{116-119}$ ) to the high-temperature cubic structure via either one (or more) intermediate-temperature phases. ${ }^{62,120,121}$
The local site symmetry at the calcium is $m$, which will slightly restrict the potential values for some NMR parameters (see Fig. 1i for local Ca environment). Prior ${ }^{17} \mathrm{O},{ }^{122}{ }^{43} \mathrm{Ca},{ }^{34,123}$ and ${ }^{47 / 49} \mathrm{Ti}^{124} \mathrm{SSNMR}$ data exist for $\mathrm{CaTiO}_{3}$, but no measurement of the ${ }^{43} \mathrm{Ca}$ shift anisotropy has been reported. $\mathrm{A}{ }^{43} \mathrm{Ca}$ MAS SSNMR experiment at $21.1 \mathrm{~T}$ using a freshly calcined sample of $\mathrm{CaTiO}_{3}$ (see Fig. S21, ESI $\dagger$ for the pXRD diffractogram) yields a spectrum which is clearly broadened by the second-order QI and which is non-axially symmetric $\left(C_{\mathrm{Q}}{ }^{43} \mathrm{Ca}\right)=2.09(0.05) \mathrm{MHz} ; \eta_{\mathrm{Q}}=$ $0.75(0.05)$, Fig. 11b). These present values are in excellent agreement with the prior literature values.

Static ${ }^{43} \mathrm{Ca}$ SSNMR experiments at $B_{0}=21.1$ and $11.75 \mathrm{~T}$ (Fig. 11d and Fig. S22, ESI $\dagger$ ) establish that the calcium CS tensor for $\mathrm{CaTiO}_{3}$ is rather large $(\Omega=53(3) \mathrm{ppm})$ and nearly axially symmetric $(\kappa=0.8(0.1))$. GIPAW DFT calculations using the structure of Ali and Yashima ${ }^{62}$ result in EFG and CS tensor parameters which agree well with experiment, although the calculated $\Omega$ value overestimates the experimental value by about $20 \%$.

\section{J. Enriched calcium nitrate, ${ }^{43} \mathrm{Ca}\left(\mathrm{NO}_{3}\right)_{2}$}

Under normal atmospheric conditions, $\mathrm{Ca}\left(\mathrm{NO}_{3}\right)_{2}$ will freely absorb ambient water, with the most stable water solvate being the $\alpha$-tetrahydrate, ${ }^{125,126}$ although many other hydrated and solvated forms of calcium nitrate may be prepared. ${ }^{127,128}$ The crystal structure for anhydrous calcium nitrate was determined approximately 90 years ago by XRD methods, ${ }^{129}$ and does not appear to have been updated since $1931 .^{63}$ The crystal structure belongs to the cubic $P a \overline{3}$ space group, with calcium cations being positioned on high symmetry $\overline{3}$ sites (Fig. 1j), which should confer axial symmetry on the CS and EFG tensors for calcium. Solid-state ${ }^{43} \mathrm{Ca}$ NMR experiments have not been previously reported for the anhydrous form, but ${ }^{43} \mathrm{Ca}$ NMR data exist for $\mathrm{Ca}\left(\mathrm{NO}_{3}\right)_{2} \cdot 4 \mathrm{H}_{2} \mathrm{O} .{ }^{35}$ Calcium-43 NMR experiments were carried out on this material at both $B_{0}=9.4$ and $21.1 \mathrm{~T}$, and generally yield "textbook" quality signals which are clearly broadened by the second-order QI, even at our highest $B_{0}$ $\left(C_{\mathrm{Q}}{ }^{43} \mathrm{Ca}\right)=1.57(0.01) \mathrm{MHz} ; \eta_{\mathrm{Q}}=0.0$; Fig. 12; for data acquired at $9.4 \mathrm{~T}$, see Fig. S23 of the ESI $\dagger$ ). 

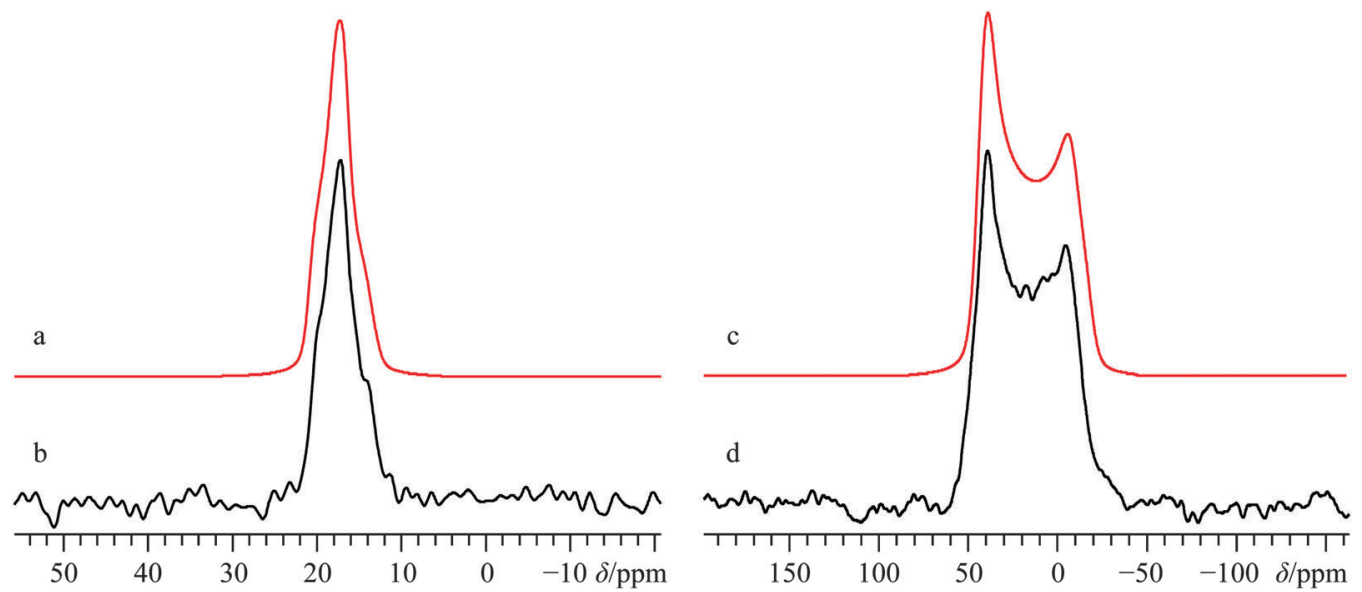

Fig. 11 Analytical line shape simulations (a, c) and experimental (b, d) ${ }^{43} \mathrm{Ca}$ MAS $\left(\nu_{\mathrm{MAS}}=5.0 \mathrm{kHz}\right.$, b) and static (d) $\mathrm{SSNMR}_{\text {spectra of CaTiO }}$, acquired at $B_{0}=21.1 \mathrm{~T}$. The experimental spectra result from the collection of 13133 transients with a recycle delay of $5.0 \mathrm{~s}$ (experiment time $\left.=18.2 \mathrm{~h}, \mathrm{~b}\right)$, and from 29071 transients with a recycle delay of $5.0 \mathrm{~s}$ (experiment time $=40.4 \mathrm{~h}, \mathrm{~d}$ ).
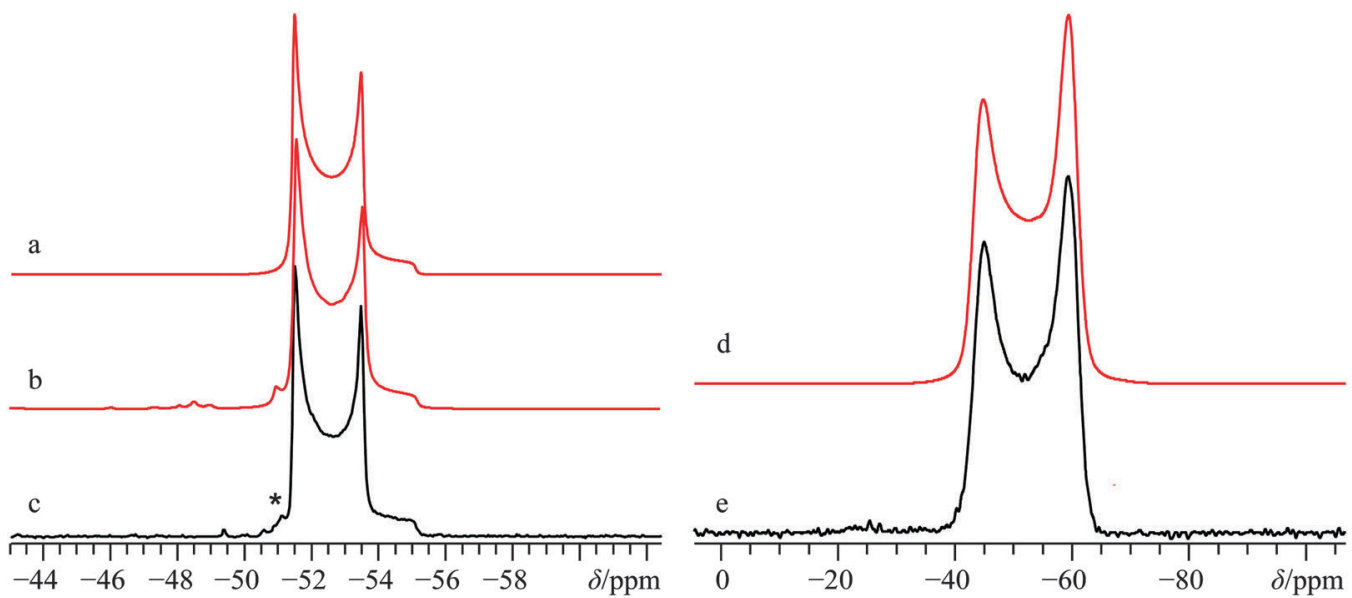

Fig. 12 Analytical line shape simulations (a, d), numerical line shape simulation (b), and experimental (c, e) ${ }^{43} \mathrm{Ca}$ MAS $\left(\nu_{\mathrm{MAS}}=5.0 \mathrm{kHz}, \mathrm{c}\right)$ and static SSNMR (e) spectra of ${ }^{43} \mathrm{Ca}\left(\mathrm{NO}_{3}\right)_{2}$, (enriched to ca. $7 \%$ in ${ }^{43} \mathrm{Ca}$ ) acquired at $B_{0}=21.1 \mathrm{~T}$. The experimental spectra result from the collection of 64 transients with a recycle delay of $7.0 \mathrm{~s}$ (experiment time $=7.5 \mathrm{~min}, \mathrm{c}$ ), and from 640 transients with a recycle delay of $10.0 \mathrm{~s}$ (experiment time $=1.8 \mathrm{~h}, \mathrm{e}$ ). The asterisk in (c) denotes a small amount of signal intensity from the calcium satellite transitions, which are reproduced in the numerical line shape simulations.

The calcium CSA is rather small relative to other systems studied, $(\Omega=11.4(1.0) \mathrm{ppm})$ and the data are consistent with an axially symmetric shift tensor $(\kappa=1)$. We did not find any enhancement in the agreement when allowing for non-zero Euler angles in our modelling; hence, the EFG and CS tensor frames are assumed to be coincident. While the precision of the measured NMR tensor parameters for $\mathrm{Ca}\left(\mathrm{NO}_{3}\right)_{2}$ is relatively high, it is rather noteworthy that for this system, GIPAW DFT calculations are not able to reproduce the calculated ${ }^{43} \mathrm{Ca}$ EFG tensor magnitude using the available structure. ${ }^{63}$ At the same time, this finding is not terribly surprising given the relatively old source data for the crystal structure of $\mathrm{Ca}\left(\mathrm{NO}_{3}\right)_{2}$. Additionally, even 80 years ago, it was appreciated that the published crystal structure for $\mathrm{Ca}\left(\mathrm{NO}_{3}\right)_{2}$ was likely unsatisfactory, ${ }^{130}$ as it did not consider the very likely possibility of nitrate group rotations at ambient temperatures (see Fig. S24, ESI $\dagger$ for the pXRD diffractogram of the $\mathrm{Ca}\left(\mathrm{NO}_{3}\right)_{2}$ sample used in the NMR measurements).
Based on the axial tensor symmetry exhibited at the Ca sites, we conclude that the local site symmetry is at least $C_{3}$, which is consistent with the accepted structure. With these points in mind, we carried out an optimization of the crystal structure for this system (holding the calcium ions on the high symmetry positions), but note that the agreement between calculated and experimental ${ }^{43} \mathrm{Ca}$ NMR tensor parameters remains rather poor, especially when considered relative to the very good agreement for the other systems in this study.

\section{K. Calcium hydride, $\mathrm{CaH}_{2}$}

As a simple binary compound of calcium, it is interesting to note that very recent efforts have been expended to determine the crystal structure for $\mathrm{CaH}_{2}$, likely due to its potential as a hydrogen storage material. Although consistently observed to belong to the Pnma space group, ${ }^{131,132}$ recent neutron diffraction experiments were used to comment on the non-identical 

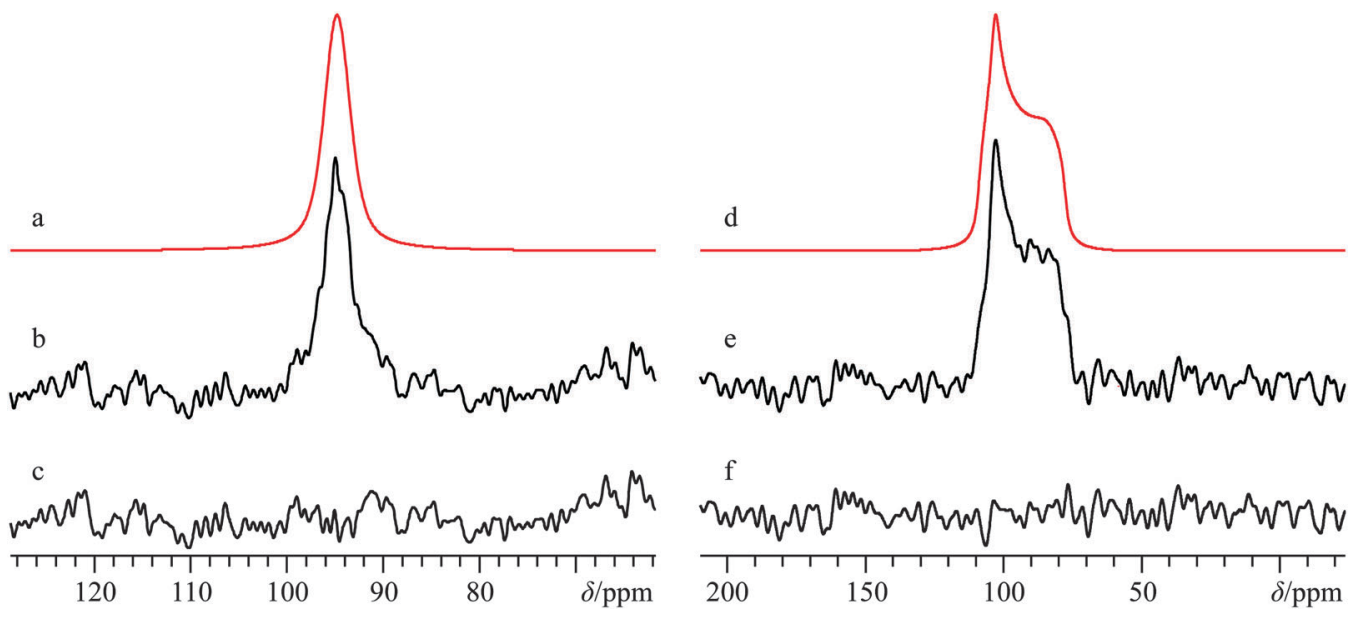

Fig. 13 Analytical line shape simulations (a, d) experimental (b, e) ${ }^{43} \mathrm{Ca}$ MAS $\left(\nu_{\text {MAS }}=5.0 \mathrm{kHz}\right.$, b) and static ${ }^{43} \mathrm{Ca}\left\{{ }^{1} \mathrm{H}\right\}$ (e) SSNMR spectra of CaH $\mathrm{S}_{2}$ along with corresponding difference spectra in $(\mathrm{c})$ and $(\mathrm{f})$, acquired at $B_{0}=21.1 \mathrm{~T}$. The experimental spectra result from the collection of 3072 transients with a recycle delay of $40.0 \mathrm{~s}$ (experiment time $=34.1 \mathrm{~h}$ ) for (b), and from 5216 transients with a recycle delay of $40.0 \mathrm{~s}$ (experiment time $=58.0 \mathrm{~h}$ ) for (e).

nature of each hydrogen atom in the asymmetric unit, as well as the poor representation provided by approximating the constituent atoms as spheres. ${ }^{64}$ The 9-coordinate $\mathrm{Ca}^{2+}$ ions lie on mirror planes, which somewhat restricts the Euler angles between the CS and EFG tensor frames (Fig. 1k). Only the peak position in a featureless ${ }^{43} \mathrm{Ca}$ MAS NMR spectrum obtained at one applied field was reported previously for this system, ${ }^{35}$ but more detailed ${ }^{1} \mathrm{H}\left(\mathrm{CaH}_{2}\right)$ and ${ }^{2} \mathrm{H}$ SSNMR $\left(\mathrm{CaD}_{2}\right)$ measurements have been carried out. ${ }^{133}$ Our present NMR experiments on $\mathrm{CaH}_{2}$ were performed at natural abundance in ${ }^{43} \mathrm{Ca}$, and by careful measurements under MAS conditions at three magnetic fields $\left(B_{0}=9.4 \mathrm{~T}, 11.75 \mathrm{~T}\right.$, and $\left.21.1 \mathrm{~T}\right)$, we were able to arrive at a set of EFG tensor parameters and a $\delta_{\text {iso }}{ }^{43} \mathrm{Ca}$ ) value (Fig. 13b and Fig. S25, as well as Fig. S26, ESI $\dagger$ for pXRD results). The primary difficulty arises from the relatively featureless ${ }^{43} \mathrm{Ca}$ NMR spectrum under MAS conditions, even at 9.4 T. This is indicative of a relatively small $C_{\mathrm{Q}}\left({ }^{43} \mathrm{Ca}\right)$ value of $1.2(0.1) \mathrm{MHz}$. We also note that the line shape models are not very sensitive to the $\eta_{\mathrm{Q}}$ value, which leads to large errors associated with its measurement $\left(\eta_{\mathrm{Q}}=0.7(0.2)\right)$. The high chemical shift value $\left(\delta\left({ }^{43} \mathrm{Ca}\right)=95.8(1.0) \mathrm{ppm}\right)$ could be anticipated due to the large amount of charge transfer believed to exist in this system, and consequently very low contributions to magnetic shielding at the calcium (i.e., positive chemical shifts).

Due to the very high quality of the neutron diffraction data, we find excellent agreement between the GIPAW DFT-calculated and experimental ${ }^{43} \mathrm{Ca}$ NMR tensor parameters for this system, although the calculated $\delta_{\text {iso }}$ value is overestimated.

\section{Natural samples of calcium carbonate, $\mathrm{CaCO}_{3}$}

Much recent effort has been expended in characterizing the natural formation of $\mathrm{CaCO}_{3} \cdot{ }^{134,135}$ While not the typical polymorph formed immediately during biomineralization, the calcite polymorph is considered to be the most stable form of $\mathrm{CaCO}_{3}$ under ambient conditions. ${ }^{136}$ Along with calcite, the aragonite polymorph (Fig. 11) is typically present in natural samples, and while several accounts have led to a full characterization of the polymorphic forms of $\mathrm{CaCO}_{3}$ by ${ }^{43} \mathrm{Ca}$ SSNMR, ${ }^{34,67,68}$ we are not aware of any attempts to characterize a naturally occurring sample of $\mathrm{CaCO}_{3}$. As such, we performed experiments on two natural samples of $\mathrm{CaCO}_{3}$, one from Cuban coral, and one from a river clam pearl. Casual inspection of the ${ }^{43}$ Ca MAS NMR spectra and pXRD spectra (Fig. S27 and S28, respectively, $\mathrm{ESI} \dagger$ ) made it clear that both samples of $\mathrm{CaCO}_{3}$ contained the aragonite polymorph exclusively. As noted earlier, the $C_{\mathrm{Q}}\left({ }^{43} \mathrm{Ca}\right)$ value for this polymorph is very small, measured to be $c a .260 \mathrm{kHz}$ by Chan and co-workers using samples which had been modestly enriched in ${ }^{43} \mathrm{Ca}^{68}$ To determine the $C_{\mathrm{Q}}\left({ }^{43} \mathrm{Ca}\right)$ value for the natural samples, ${ }^{43} \mathrm{Ca}$ MAS SSNMR experiments were carried out at $B_{0}=11.75$ and $21.1 \mathrm{~T}$. Experiments at the highest field were performed with relatively slow MAS $\left(\nu_{\text {MAS }}=\right.$ $3000 \mathrm{~Hz}$ ) and used non-CT-selective pulses to excite all singlequantum transitions as uniformly as possible. Line shape analysis using all the data yields: $C_{\mathrm{Q}}=250(50) \mathrm{kHz}, \eta_{\mathrm{Q}}=$ $0.4(0.1)$, and $\delta_{\text {iso }}=-27.0(0.4) \mathrm{ppm}$.

With the EFG tensor parameters and $\delta_{\text {iso }}$ value accurately determined, static ${ }^{43} \mathrm{Ca}$ SSNMR experiments were performed on both natural samples to see if there was any variation in the CS tensor parameters between: (i) natural samples and synthetic samples and (ii) between natural samples taken from different sources. Perhaps not surprisingly, we find that the variation in the CS tensor parameters between natural samples of aragonite is within experimental error (Fig. 14), which highlights that from the local perspective probed by ${ }^{43} \mathrm{Ca}$ SSNMR, the structures are similar. When taken in tandem with pXRD measurements that probe long-range crystalline order (see ESI, $\dagger$ Fig. S28), we conclude that for these natural samples, there is a high level of similarity between the natural samples and between natural and synthetic samples of aragonite.

While there could be slight differences in the ${ }^{43} \mathrm{Ca}$ NMR tensor parameters between natural samples (Table 2), the data are not of sufficient $\mathrm{S} / \mathrm{N}$ to distinguish these subtle differences. 


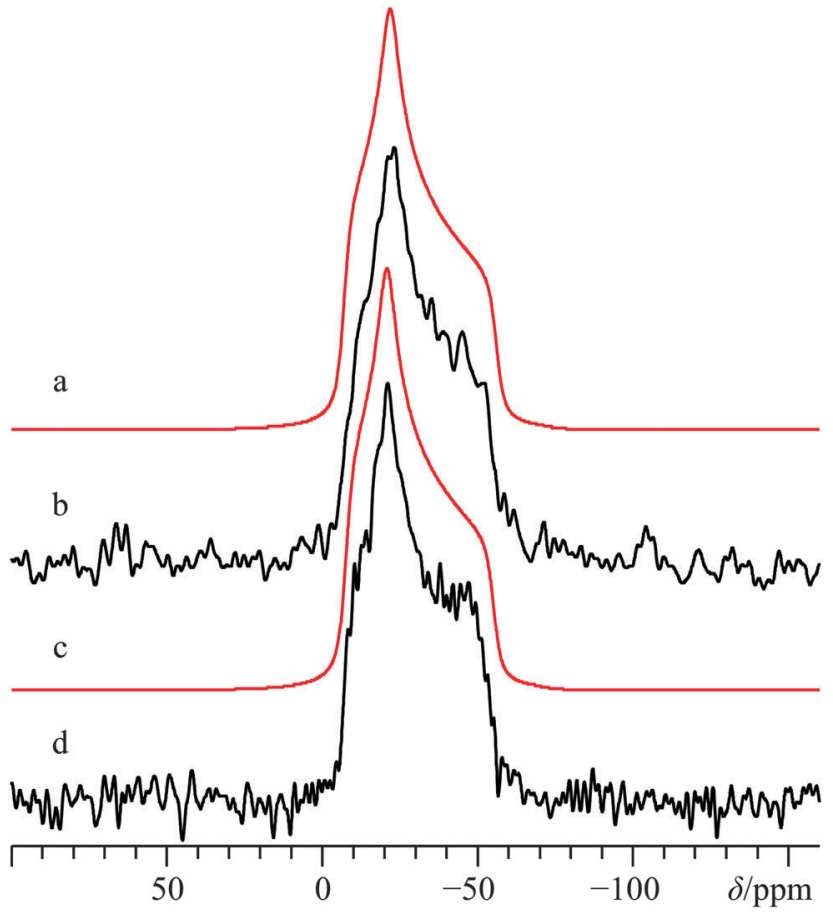

Fig. 14 Analytical line shape simulations ( $a, c)$, and experimental (b, d) static ${ }^{43} \mathrm{Ca}$ SSNMR spectra of natural samples of the aragonite polymorph of $\mathrm{CaCO}_{3}$, as found in Cuban coral (b) and the pearl of a river clam (d), acquired at $B_{0}=$ 21.1 $\mathrm{T}$. The experimental spectra result from the collection of 20000 transients with a recycle delay of $1.5 \mathrm{~s}$ (experiment time $=8.3 \mathrm{~h}$ ) for (b), and from 12000 transients with a recycle delay of $2.0 \mathrm{~s}$ (experiment time $=6.7 \mathrm{~h}$ ) for $(\mathrm{d})$.

\section{Quantum chemical calculations}

As highlighted above, high-quality crystal structures exist for nearly all of the systems under study here. As such, we used GIPAW DFT to calculate the magnetic shielding and EFG tensor parameters, and compared these with the experimentally measured parameters, where possible. The vast majority of the calculated results can be found in Table 3, with additional calculations presented in the ESI, $\uparrow$ Table S5. i. Calcium magnetic shielding tensors. Using the most recent calcium pseudopotential (see ESI, $\uparrow$ Table $\mathrm{S} 4$ footnotes), we note that the agreement between calculated and experimental CS tensors is generally good, especially for calcium $\delta_{\text {iso }}$ values. Making use of the transformation from magnetic shielding to chemical shifts of Moudrakovski et al., ${ }^{77}$ we present selected comparison charts for calcium CS tensor parameters ( $\delta_{\text {iso }}$ and $\Omega$ ) in Fig. 15.

Linear correlations with correlation coefficients near unity are observed when comparing the computed and experimental $\delta_{\text {iso }}\left(R^{2}=0.988\right)$ and $\Omega\left(R^{2}=0.885\right)$ values. For the calculated $v s$. experimental $\Omega$ values, we make the typical observation that the calculated values are nearly always greater than the experimental values (as observed with, for example, ${ }^{13} \mathrm{C}$ ). ${ }^{137}$ We rationalize this as being due to dynamics which may occur at room temperature, which will partially average the observed $\Omega$. As isotropic values are not affected as strongly in this manner, we see a higher level of correlation between experimental and calculated $\delta_{\text {iso }}$ values.

ii. $\quad{ }^{43}$ Ca EFG tensors. Using the $Q$ value of Sahoo, ${ }^{138}$ which has been demonstrated to yield computed $\left|C_{\mathrm{Q}}\left({ }^{43} \mathrm{Ca}\right)\right|$ values that are in better agreement with experimental values, ${ }^{65}$ we observe reasonably high $\left(R^{2}\right.$ values both greater than 0.86$)$ correlation between the experimental and GIPAW DFT-computed values for the $C_{\mathrm{Q}}$ and $\eta_{\mathrm{Q}}$ parameters which define the EFG tensor (Fig. 16). When generating the line of best-fit to the data for $\left|C_{\mathrm{Q}}\left({ }^{43} \mathrm{Ca}\right)\right|$, we excluded the data point for $\mathrm{Ca}\left(\mathrm{NO}_{3}\right)_{2}$ (red point in Fig. 16a), as it was an outlier.

We postulate that the reason for the poor agreement for $\mathrm{Ca}\left(\mathrm{NO}_{3}\right)_{2}$ may stem from the age (and hence poor resolution) of the accepted crystal structure. As outlined below, very small alterations in the crystalline lattice should result in dramatic changes in the observable calcium NMR tensor parameters. Importantly, the GIPAW DFT and experimental measurements seem to consistently agree that the calcium atom is on a site of axial symmetry ( $\eta_{\mathrm{Q}}$ equal to or approaching 0 ). Axial EFG tensor symmetry can be used in NMR crystallography approaches to restrict the local symmetry at the nuclear site. ${ }^{75}$
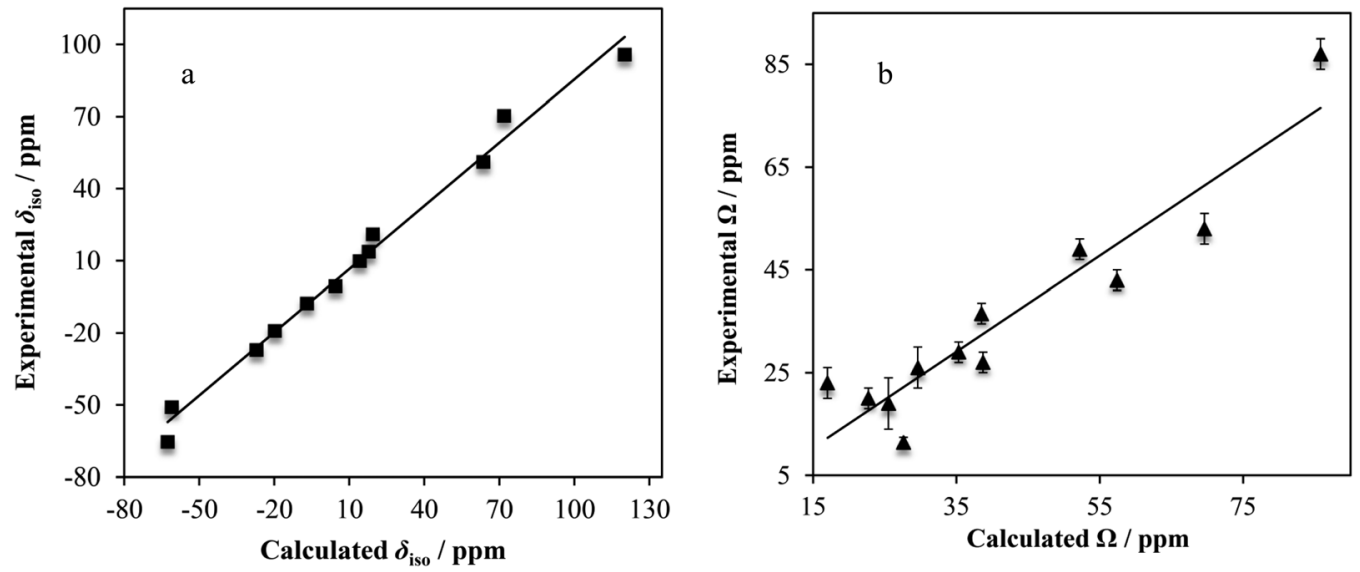

Fig. 15 Experimental vs. GIPAW DFT-computed calcium chemical shift tensor parameters $\left(\delta_{\text {iso, }} \mathrm{a} ; \Omega, \mathrm{b}\right)$ for many of the systems under study. Lines of best-fit are displayed (in a, $\delta_{\text {iso }}($ exp. $/ \mathrm{ppm})=0.877 \delta_{\text {iso }}$ (calc. $\left./ \mathrm{ppm}\right)-2.14, R^{2}=0.988$; in b, $\Omega($ exp. $\left./ \mathrm{ppm})=0.933 \Omega(\mathrm{calc} . / \mathrm{ppm})-3.57, R^{2}=0.885\right)$. Experimental error bars are actually present in both above plots, but lie within the data points of (a). 

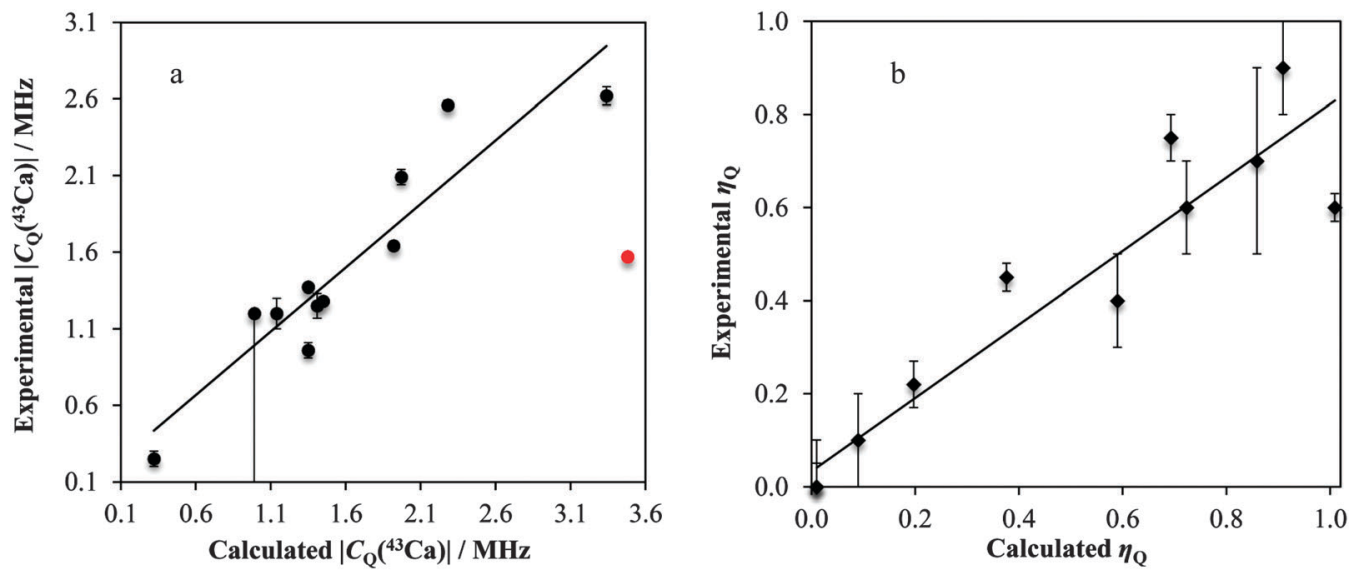

Fig. 16 Experimentally observed vs. GIPAW DFT-computed EFG tensor parameters $\left(\left|C_{Q}\left({ }^{43} C a\right)\right|, a ; \eta_{Q}, b\right)$ for many of the systems under study. The $\left|\mathrm{C}_{\mathrm{Q}}\left({ }^{43} \mathrm{Ca}\right)\right|$ datum for $\mathrm{Ca}\left(\mathrm{NO}_{3}\right)_{2}$ is not included in the fitting (red point). Lines of best-fit are displayed (in a, $\mathrm{C}_{\mathrm{Q}}(\mathrm{exp} . / \mathrm{MHz})=0.832 \mathrm{C}_{\mathrm{Q}}(\mathrm{calc} . / \mathrm{MHz})+0.168$, $R^{2}=0.864$; in b, $\eta_{Q}$ (exp.) $=0.790 \eta_{Q}($ calc. $\left.)+0.0408, R^{2}=0.883\right)$.

iii. Sensitivity of calcium NMR tensors to structure in $\mathrm{Ca}(\mathrm{OH})_{2}$ and $\mathrm{CaCrO}_{4}$. As the calcium CS and EFG tensors of $\mathrm{Ca}(\mathrm{OH})_{2}$ and $\mathrm{CaCrO}_{4}$ were measured with rather high precision, we chose these two systems to further comment upon the sensitivity of calcium NMR tensor parameters to minor modifications in structure. Starting from the accepted crystal structures denoted earlier, we modeled structural changes by isotropic unit cell expansions or contractions ( $a b c$ crystal basis), and monitored the changes in calculated GIPAW DFT NMR tensor parameters.

For $\mathrm{Ca}(\mathrm{OH})_{2}$, we observe significant changes in both the $\delta_{\text {iso }}$ and $\left|C_{\mathrm{Q}}\left({ }^{43} \mathrm{Ca}\right)\right|$ values (Fig. 17), with the other tensor parameters remaining largely unchanged (for example, $\Omega$, see ESI, $\dagger$ Fig. S29). The data suggest that alterations of the unit cell and calcium-oxygen first coordination sphere internuclear distances by as little as $1 \%$ could be detected through changes in $C_{\mathrm{Q}}\left({ }^{43} \mathrm{Ca}\right)$ and $\delta_{\text {iso }}$ for $\mathrm{Ca}(\mathrm{OH})_{2}$. It is important to note that these NMR parameters can be simultaneously measured using primarily MAS experiments, which are much more sensitive for ${ }^{43} \mathrm{Ca}$ compared to the static experiments. This finding offers hope that these parameters could be meaningfully used as structural restraints in crystal structure refinements, as demonstrated recently for other quadrupolar nuclei in the solid state. ${ }^{139,140}$

Likewise, for $\mathrm{CaCrO}_{4}$ we observe a similar sensitivity in $\left|C_{\mathrm{Q}}\left({ }^{43} \mathrm{Ca}\right)\right|$ and $\delta_{\text {iso }}$ to small changes in the crystal lattice dimensions (and hence also calcium-oxygen first coordination sphere distances; ESI, $\uparrow$ Fig. S30). Notably, for this system we also calculate that the CS tensor span $(\Omega)$ would serve as a very sensitive probe of small structural changes (Fig. 18). Of course, measurement of the CS tensor for calcium remains challenging, but we anticipate that our present findings will motivate future studies which involve the measurement of calcium CS tensors.
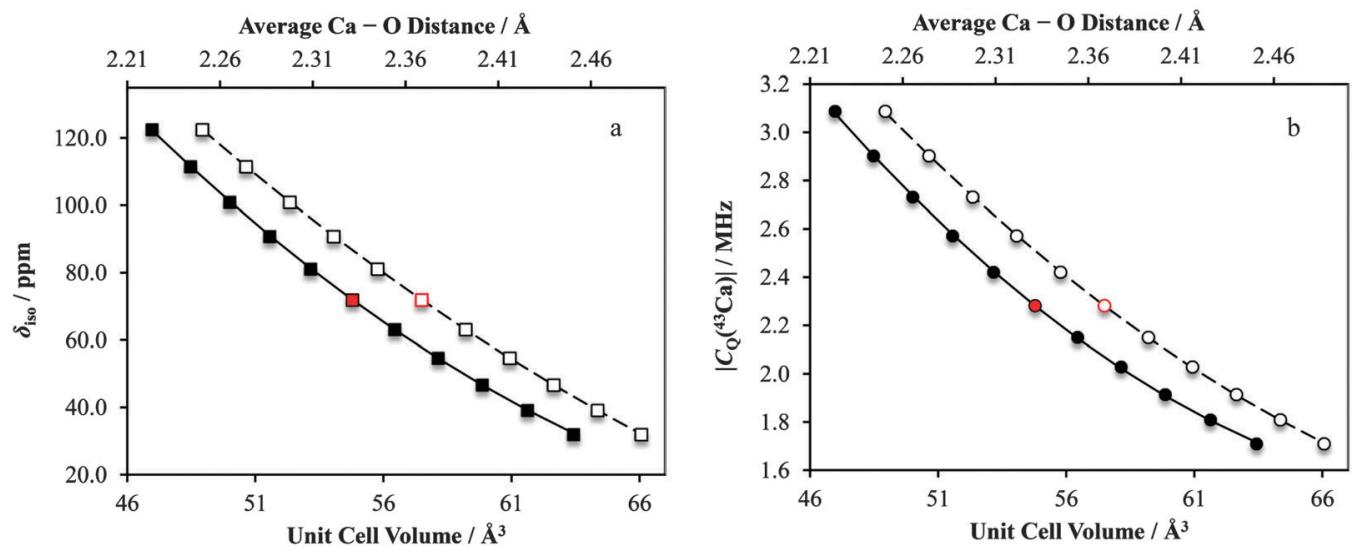

Fig. 17 Results of GIPAW DFT computations which highlight the profound sensitivity of both the isotropic calcium chemical shift, as well as the $\left|C_{Q}\left({ }^{43} \mathrm{Ca}\right)\right|$ value to minor alterations in $\mathrm{Ca}(\mathrm{OH})_{2}$ structural parameters. The data points indicated in red correspond to the respective parameters calculated using the accepted crystal structure. Solid data points correspond to lower horizontal axis. Second-degree polynomial lines of best fit: in a, $\delta_{\text {iso }}=0.112\left(V_{\text {cell }}\right)^{2}-17.8\left(V_{\text {cell }}\right)+713, R^{2}=0.999 ;$ in b, $\left|C_{Q}\left({ }^{43} \mathrm{Ca}\right)\right|=0.00223\left(V_{\text {cell }}\right)^{2}-0.329\left(V_{\text {cell }}\right)+13.6, R^{2}=0.999$, where $V_{\text {cell }}$ is the unit cell volume in $\AA^{3}$. Open data points correspond to upper horizontal axis. Second-degree polynomial lines of best fit: in a, $\delta_{\text {iso }}=382.7\left(r_{\mathrm{Ca}-\mathrm{O}}\right)^{2}-2195\left(r_{\mathrm{Ca}-\mathrm{O}}\right)+3124$, $R^{2}=1.00$; in $\mathrm{b},\left|C_{\mathrm{Q}}\left({ }^{43} \mathrm{Ca}\right)\right|=8.40\left(r_{\mathrm{Ca}-\mathrm{O}}\right)^{2}-45.6\left(r_{\mathrm{Ca}-\mathrm{O}}\right)+63.1, R^{2}=1.00$, where $r_{\mathrm{Ca}-\mathrm{O}}$ is the average calcium-oxygen distance in $\AA$. 


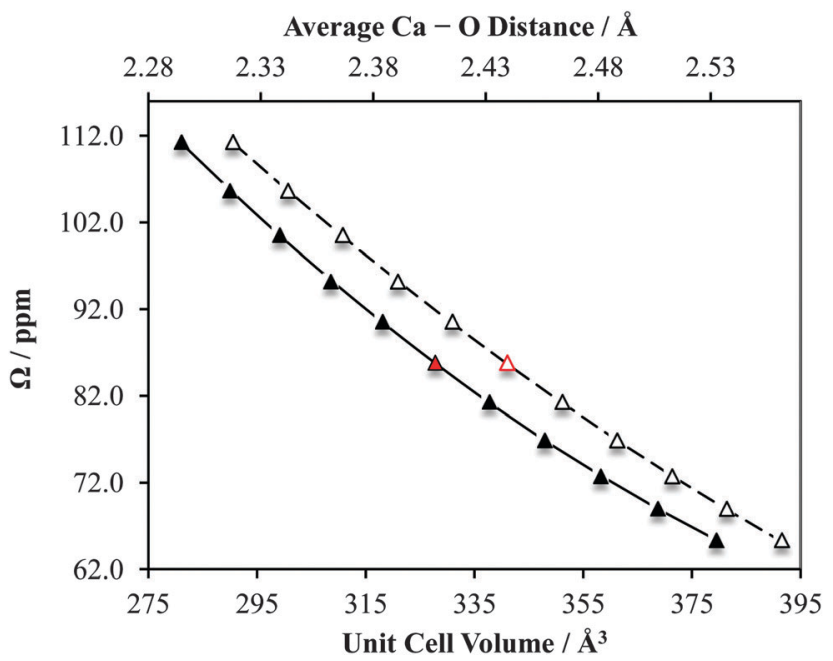

Fig. 18 Results of GIPAW DFT computations which highlight the sensitivity of the calcium chemical shift tensor span $(\Omega)$ to alterations in $\mathrm{CaCrO}_{4}$ structural parameters. The data points indicated in red correspond to $\Omega$ calculated using the accepted crystal structure. Solid data points correspond to lower horizontal axis. Second-degree polynomial line of best fit: $\Omega=0.00152\left(V_{\text {cell }}\right)^{2}-1.47\left(V_{\text {cell }}\right)+404 ; R^{2}=0.999$. Open data points correspond to upper horizontal axis. Second-degree polynomial line of best fit: $\Omega=169.8\left(r_{\mathrm{Ca}-\mathrm{O}}\right)^{2}-1017\left(r_{\mathrm{Ca}-\mathrm{O}}\right)+1556 ; R^{2}=1.00$.

As noted earlier, the observed calcium CS tensor $\Omega$ value for $\mathrm{CaCrO}_{4}$ is the largest measured to date. This could be reasonably anticipated due to the presence of a transition metal species near to the calcium. When considering the full calcium CS tensor, which includes the associated eigenvectors, it is seen that $\delta_{11}$ (the most de-shielded component) points exactly towards the most proximate chromium $\left(r_{\mathrm{Ca}-\mathrm{Cr}}=3.142 \AA\right)$, as depicted in Fig. 19a. Due to the symmetry of the calcium CS tensor for $\mathrm{CaCrO}_{4}(\kappa=-1)$, the other two CS tensor eigenvectors $\left(\delta_{22}\right.$ and $\left.\delta_{33}\right)$ define a plane of equivalent magnetic shielding which is oriented perpendicular to the $\mathrm{Ca}-\mathrm{Cr}$ internuclear vector. The enhanced de-shielding in the direction of the $\mathrm{Cr}$ is consistent with larger contributions to the paramagnetic shielding mechanism, ${ }^{141-144}$ which is often seen in transition metals, and is due to the various d orbitals available. ${ }^{145}$ We also note that this directional dependence can explain the very pronounced changes in the calcium CS tensor as a function of the small unit cell changes that were shown in Fig. 18. While both the parallel and perpendicular components of the Ca CS tensor are sensitive to unit cell variation, GIPAW DFT computations make it clear that the component which lies in the direction of the $\mathrm{Ca}-\mathrm{Cr}$ internuclear bond vector (i.e., $\delta_{11}$ ) changes more rapidly relative to the components which lie perpendicular to this direction (i.e., $\delta_{22} / \delta_{33}$; Fig. 19b).

\section{Conclusions}

Using a variety of modern experimental NMR spectroscopy techniques, including cross-polarization and population transfer, ${ }^{43} \mathrm{Ca}$ solid state NMR data for a broad selection of common calciumcontaining materials have been acquired and interpreted. Importantly, by acquiring data at both standard (9.4 and 11.75 T) and very high (21.1 T) applied magnetic fields, and by using MAS and static data acquisition, we were able to measure 13 calcium chemical shift tensors, which roughly triples the amount of data available in the literature. For a few select cases, modest isotopic enrichment in ${ }^{43} \mathrm{Ca}$ ( $\mathrm{ca}$. 7\%) was used to enable very high quality data acquisition. By coupling our experimental data with GIPAW DFT computations using accepted crystal structures, we were able to calculate, with reasonably high accuracy, the EFG and magnetic shielding tensors for nearly all of the samples considered. These results indicate that ${ }^{43} \mathrm{Ca}$ solid-state NMR experiments would be valuable probes for distinguishing polymorphs (for example, $\alpha-v s$. $\beta$-calcium formate) and hydrates (for example, $\mathrm{CaCl}_{2}$ and calcium tartrate hydrates). While demonstrated for nearly all
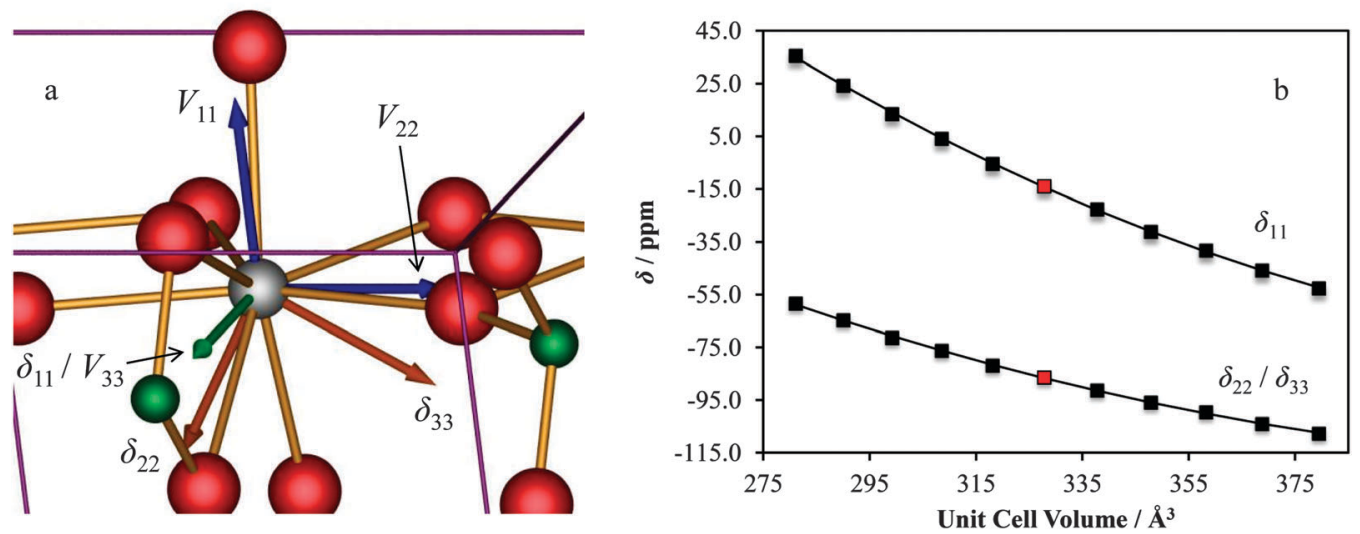

Fig. 19 GIPAW DFT results for $\mathrm{CaCrO}_{4}$ which display (a) the computed EFG and CS tensor eigenvectors and (b) the sensitivity of the calcium chemical shift tensor eigenvalues to alterations in $\mathrm{CaCrO}_{4}$ structural parameters. For (a): POV-Ray rendering of the computed EFG tensor $\left(V_{i i}, i=1,2,3\right.$, in blue) and chemical shift ( $\delta_{i i}$, orange) eigenvectors in the unit cell reference frame. When the EFG and CS tensor eigenvectors overlap (as for $V_{33}$ and $\delta_{11}$ ), they are displayed in green. For (b): red data points correspond to values calculated using the accepted crystal structure. Second-degree polynomial lines of best fit: $\delta_{11} / \mathrm{ppm}=0.00321\left(V_{\text {cell }}\right)^{2}-3.00\left(V_{\text {cell }}\right)+626 ; R^{2}=1.00 ; \delta_{33} / \mathrm{ppm}=\delta_{22} / \mathrm{ppm}=0.00194\left(V_{\text {cell }}\right)^{2}-1.77\left(V_{\text {cell }}\right)+286 ; R^{2}=0.999$. 
of the samples considered here using only 1D NMR experiments, extracting full tensor information for systems with many calcium chemical sites will be exceptionally challenging due to resolution issues. It is also shown for two samples used herein, that the local calcium structure for natural samples of aragonite from different sources is retained. We also demonstrated, using $\mathrm{Ca}(\mathrm{OH})_{2}$ and $\mathrm{CaCrO}_{4}$ as representative examples, that both the calcium EFG tensor and the calcium chemical shift tensor are extremely sensitive probes of modest structural changes in the unit cell volume and the average calcium-oxygen first coordination sphere distance. As such, with further continued advances in solid-state NMR apparatus and signal enhancement techniques, these NMR observables could potentially find general application in NMR crystallographic structural refinement protocols, and potentially even structural determinations.

\section{Acknowledgements}

C.M.W. and D.L.B. are grateful to the Natural Sciences and Engineering Research Council (NSERC) for funding. Access to the $900 \mathrm{MHz}$ NMR spectrometer was provided by the National Ultrahigh-Field NMR Facility for Solids (Ottawa, Canada), a national research facility funded by the Canada Foundation for Innovation, the Ontario Innovation Trust, Recherche Québec, the National Research Council Canada, and Bruker BioSpin and managed by the University of Ottawa (www.nmr900.ca). NSERC is acknowledged for a Major Resources Support grant. We are also grateful for the technical support provided by Dr V. Terskikh and Dr E. Ye at the high-field NMR facility and by Dr Tara Kell (uOttawa core X-ray facility) and Mr Kevin M. N. Burgess for recording the powder XRD spectra. We thank Mr Dominic Aebi for early work on this project, which resulted in the synthesis of the racemic calcium tartrate tetrahydrate sample.

\section{References}

1 Calcium: A Matter of Life or Death, ed. J. Krebs and M. Michalak, Elsevier, Amsterdam, 2007.

2 D. W. Rooklin, M. Lu and Y. Zhang, J. Am. Chem. Soc., 2012, 134, 15595-15603.

3 M. B. Johny, P. S. Yang, H. Bazzazi and D. T. Yue, Nat. Commun., 2013, 4, 1717.

4 P. Yuan, M. D. Leonetti, Y. Hsiung and R. MacKinnon, Nature, 2012, 481, 94-97.

5 S. Forsén and B. Lindman, Annu. Rep. NMR Spectrosc., 1981, 11, 183-226.

6 H. Wang, J. S. Tse, K. Tanaka, T. Iitaka and Y. Ma, Proc. Natl. Acad. Sci. U. S. A., 2012, 109, 6463-6466.

7 W. Schnelle, A. Ormeci, A. Wosylus, K. Meier, Y. Grin and U. Schwarz, Inorg. Chem., 2012, 51, 5509-5511.

8 K. Kanetani, K. Sugawara, T. Sato, R. Shimizu, K. Iwaya, T. Hitosugi and T. Takahashi, Proc. Natl. Acad. Sci. U. S. A., 2012, 109, 19610-19613.

9 Y.-L. Li, W. Luo, Z. Zeng, H.-Q. Lin, H.-k. Mao and R. Ahuja, Proc. Natl. Acad. Sci. U. S. A., 2013, 110, 9289-9294.
10 J. S. Wixey and B. D. Ward, Chem. Commun., 2011, 47, 5449-5451.

11 J. Spielmann, F. Buch and S. Harder, Angew. Chem., Int. Ed., 2008, 47, 9434-9438.

12 S. Harder, Chem. Rev., 2010, 110, 3852-3876.

13 S. Kobayashi and Y. Yamashita, Acc. Chem. Res., 2011, 44, 58-71.

14 B. Liu, J.-F. Carpentier and Y. Sarazin, Chem. - Eur. J., 2012, 18, 13259-13264.

15 J.-M. Begouin and M. Niggemann, Chem. - Eur. J., 2013, 19, 8030-8041.

16 C. B. Minella, S. Garroni, D. Olid, F. Teixidor, C. Pistidda, I. Lindemann, O. Gutfleisch, M. D. Baró, R. Bormann, T. Klassen and M. Dornheim, J. Phys. Chem. C, 2011, 115, 18010-18014.

17 H. Chu, G. Wu, Y. Zhang, Z. Xiong, J. Guo, T. He and P. Chen, J. Phys. Chem. C, 2011, 115, 18035-18041.

18 S. Horike, Y. Kamitsubo, M. Inukai, T. Fukushima, D. Umeyama, T. Itakura and S. Kitagawa, J. Am. Chem. Soc., 2013, 135, 4612-4615.

19 D. L. Bryce, Dalton Trans., 2010, 39, 8593-8602.

20 D. Laurencin and M. E. Smith, Prog. Nucl. Magn. Reson. Spectrosc., 2013, 68, 1-40.

21 I. L. Moudrakovski, Annu. Rep. NMR Spectrosc., 2013, 79, 129-240.

22 T. Andersson, T. Drakenberg, S. Forsén, E. Thulin and M. Swärd, J. Am. Chem. Soc., 1982, 104, 576-580.

23 J. M. Aramini, T. Drakenberg, T. Hiraoki, Y. Ke, K. Nitta and H. J. Vogel, Biochemistry, 1992, 31, 6761-6768.

24 H. J. Vogel and S. Forsén, Biol. Magn. Reson., 1987, 7, 249-309.

25 T. B. Coplen, J. K. Böhlke, P. De Bièvre, T. Ding, N. E. Holden, J. A. Hopple, H. R. Krouse, A. Lamberty, H. S. Peiser, K. Révész, S. E. Rieder, K. J. R. Rosman, E. Roth, P. D. P. Taylor, R. D. Vocke Jr. and Y. K. Xiao, Pure Appl. Chem., 2002, 74, 1987-2017.

26 G. M. Bowers and R. J. Kirkpatrick, J. Am. Ceram. Soc., 2009, 92, 545-548.

27 S. E. Ashbrook, Phys. Chem. Chem. Phys., 2009, 11, 6892-6905.

28 J. Autschbach, S. Zheng and R. W. Schurko, Concepts Magn. Reson., Part A, 2010, 36, 84-126.

29 V. I. Bakhmutov, Chem. Rev., 2011, 111, 530-562.

30 C. Fernandez and M. Pruski, Top. Curr. Chem., 2012, 306, 119-188.

31 T. Bräuniger and M. Jansen, Z. Anorg. Allg. Chem., 2013, 639, 857-879.

32 K. J. D. MacKenzie and M. E. Smith, Multinuclear SolidState NMR of Inorganic Materials, Pergamon, Amsterdam, 2002.

33 A. Wong, P. M. Aguiar, T. Charpentier and D. Sakellariou, Chem. Sci., 2011, 2, 815-818.

34 R. Dupree, A. P. Howes and S. C. Kohn, Chem. Phys. Lett., 1997, 276, 399-404.

35 Z. Lin, M. E. Smith, F. E. Sowrey and R. J. Newport, Phys. Rev. B: Condens. Matter Mater. Phys., 2004, 69, 224107. 
36 A. Wong, A. P. Howes, R. Dupree and M. E. Smith, Chem. Phys. Lett., 2006, 427, 201-205.

37 C. Gervais, D. Laurencin, A. Wong, F. Pourpoint, J. Labram, B. Woodward, A. P. Howes, K. J. Pike, R. Dupree, F. Mauri, C. Bonhomme and M. E. Smith, Chem. Phys. Lett., 2008, 464, 42-48.

38 R. G. Bryant, S. Ganapathy and S. D. Kennedy, J. Magn. Reson., 1987, 72, 376-378.

39 D. Laurencin, A. Wong, J. V. Hanna, R. Dupree and M. E. Smith, J. Am. Chem. Soc., 2008, 130, 2412-2413.

40 A. F. Armington and J. J. O'Connor, in Inorganic Syntheses, ed. D. H. Busch, John Wiley \& Sons, Toronto, 1980, vol. 20, pp. 1-8.

41 P. R. Bodart, J.-P. Amoureux, Y. Dumazy and R. Lefort, Mol. Phys., 2000, 98, 1545-1551.

42 A. P. M. Kentgens and R. Verhagen, Chem. Phys. Lett., 1999, 300, 435-443.

43 S. Prasad, H.-T. Kwak, T. Clark and P. J. Grandinetti, J. Am. Chem. Soc., 2002, 124, 4964-4965.

44 K. Eichele and R. E. Wasylishen, WSolids1, version 1.19.11, Universität Tübingen, Tübingen, Germany, 2009.

45 M. Bak, J. T. Rasmussen and N. C. Nielsen, J. Magn. Reson., 2000, 147, 296-330.

46 C. J. Pickard and F. Mauri, Phys. Rev. B: Condens. Matter Mater. Phys., 2001, 63, 245101.

47 S. J. Clark, M. D. Segall, C. J. Pickard, P. J. Hasnip, M. I. J. Probert, K. Refson and M. C. Payne, Z. Kristallogr., 2005, 220, 567-570.

48 J. R. Yates, C. J. Pickard and F. Mauri, Phys. Rev. B: Condens. Matter Mater. Phys., 2007, 76, 024401.

49 (a) M. Profeta, F. Mauri and C. J. Pickard, J. Am. Chem. Soc., 2003, 125, 541-548; (b) T. Charpentier, Solid State Nucl. Magn. Reson., 2011, 40,1-20; (c) C. Bonhomme, C. Gervais, F. Babonneau, C. Coelho, F. Pourpoint, T. Azaïs, S. E. Ashbrook, J. M. Griffin, J. R. Yates, F. Mauri and C. J. Pickard, Chem. Rev., 2012, 112, 5733-5779.

50 D. Vanderbilt, Phys. Rev. B: Condens. Matter Mater. Phys., 1990, 41, 7892-7895.

51 J. P. Perdew, K. Burke and M. Ernzerhof, Phys. Rev. Lett., 1996, 77, 3865-3868.

52 J. P. Perdew, K. Burke and M. Ernzerhof, Phys. Rev. Lett., 1997, 78, 1396.

53 S. Adiga, D. Aebi and D. L. Bryce, Can. J. Chem., 2007, 85, 496-505.

54 L. Desgranges, D. Grebille, G. Calvarin, G. Chevrier, N. Floquet and J.-C. Niepce, Acta Crystallogr., Sect. B: Struct. Sci., 1993, 49, 812-817.

55 E. A. Klop, A. Schouten, P. van der Sluis and A. L. Spek, Acta Crystallogr., Sect. C: Cryst. Struct. Commun., 1984, 40, 51-53.

56 N. Burger, H. Fuess and S. A. Mason, Acta Crystallogr., Sect. B: Struct. Crystallogr. Cryst. Chem., 1977, 33, 1968-1970.

57 A. Le Bail, D. Bazin, M. Daudon, A. Brochot, V. RobbezMasson and V. Maisonneuve, Acta Crystallogr., Sect. B: Struct. Sci., 2009, 65, 350-354.

58 A. LeClaire and M. M. Borel, Acta Crystallogr., Sect. B: Struct. Crystallogr. Cryst. Chem., 1977, 33, 1608-1610.
59 E. N. Caspi, B. Pokroy, P. L. Lee, J. P. Quintana and E. Zolotoyabko, Acta Crystallogr., Sect. B: Struct. Sci., 2005, 61, 129-132.

60 P. Comodi, S. Nazzareni, P. F. Zanazzi and S. Speziale, Am. Mineral., 2008, 93, 1530-1537.

61 G. Weber and K. J. Range, Z. Naturforsch., B: Chem. Sci., 1996, 51, 751-753.

62 R. Ali and M. Yashima, J. Solid State Chem., 2005, 178, 2867-2872.

63 L. Vegard and L. Bilberg, Skr. Nor. Vidensk.-Akad., [Kl.] 1: Mat.-Naturvidensk. Kl., 1931, 12, 1-22.

64 J. A. Alonso, M. Retuerto, J. Sánchez-Benítez and M. T. Fernández-Díaz, Z. Kristallogr., 2010, 225, 225-229.

65 K. M. N. Burgess, Y. Xu, M. C. Leclerc and D. L. Bryce, Inorg. Chem., 2014, 53, 552-561.

66 C. M. Widdifield and D. L. Bryce, Can. J. Chem., 2011, 89, 754-763.

67 D. L. Bryce, E. B. Bultz and D. Aebi, J. Am. Chem. Soc., 2008, 130, 9282-9292.

68 Y.-C. Huang, Y. Mou, T. W.-T. Tsai, Y.-J. Wu, H.-K. Lee, S.-J. Huang and J. C. C. Chan, J. Phys. Chem. B, 2012, 116, 14295-14301.

69 D. L. Bryce, in NMR Crystallography, ed. R. K. Harris, R. E. Wasylishen and M. J. Duer, John Wiley \& Sons, West Sussex, United Kingdom, 2009, ch. 20, pp. 289-301.

70 E. A. Harrington, Am. J. Sci., 1927, 13, 467-479.

71 H. D. Megaw, Proc. R. Soc. London, Ser. A, 1933, 142, 198-214.

72 W. R. Busing and H. A. Levy, J. Chem. Phys., 1957, 26, 563-568.

73 H. E. Petch, Acta Crystallogr., 1961, 14, 950-957.

74 O. Chaix-Pluchery, J. Pannetier, J. Bouillot and J. C. Niepce, J. Solid State Chem., 1987, 67, 225-234.

75 O. H. Han and E. Oldfield, Inorg. Chem., 1990, 29, 3666-3669.

76 A. Trokiner, A. Bessière, R. Thouvenot, D. Hau, J. Marko, V. Nardello, C. Pierlot and J.-M. Aubry, Solid State Nucl. Magn. Reson., 2004, 25, 209-215.

77 I. L. Moudrakovski, R. Alizadeh and J. J. Beaudoin, Phys. Chem. Chem. Phys., 2010, 12, 6961-6969.

78 G. Wu, D. Rovnyak, P. C. Huang and R. G. Griffin, Chem. Phys. Lett., 1997, 277, 79-83.

79 F. Blanc, L. Sperrin, D. A. Jefferson, S. Pawsey, M. Rosay and C. P. Grey, J. Am. Chem. Soc., 2013, 135, 2975-2978.

80 T. Watanabe and M. Matsui, Acta Crystallogr., Sect. B: Struct. Crystallogr. Cryst. Chem., 1978, 34, 2731-2736.

81 H. Post and U. Haeberlen, J. Magn. Reson., 1980, 40, 17-31.

82 H. Schmitt, H. Zimmermann, O. Körner, M. Stumber, C. Meinel and U. Haeberlen, J. Magn. Reson., 2001, 151, 65-77.

83 J. L. Ackerman, J. Tegenfeldt and J. S. Waugh, J. Am. Chem. Soc., 1974, 96, 6843-6845.

84 M. E. Stoll, A. J. Vega and R. W. Vaughan, J. Chem. Phys., 1976, 65, 4093-4098.

85 R. Richarz and H. Sauter, J. Magn. Reson., 1983, 52, 308-309.

86 T. Nakai, J. Ashida and T. Terao, J. Chem. Phys., 1988, 88, 6049-6058. 
87 A. E. Bennett, C. M. Rienstra, M. Auger, K. V. Lakshmi and R. G. Griffin, J. Chem. Phys., 1995, 103, 6951-6958.

88 S. Inagaki, I. Kawamura, Y. Sasaki, K. Yoshida, Y. Kubota and A. Naito, Phys. Chem. Chem. Phys., 2013, 15, 13523-13531.

89 A. Wong, D. Laurencin, G. Wu, R. Dupree and M. E. Smith, J. Phys. Chem. A, 2008, 112, 9807-9813.

90 M. Matsui, T. Watanabe, N. Kamijo, R. L. Lapp and R. A. Jacobson, Acta Crystallogr., Sect. B: Struct. Crystallogr. Cryst. Chem., 1980, 36, 1081-1086.

91 D. L. Bryce and E. B. Bultz, Chem. - Eur. J., 2007, 13, 4786-4796.

92 D. I. Kolokolov, I. S. Glaznev, Y. I. Aristov, A. G. Stepanov and H. Jobic, J. Phys. Chem. C, 2008, 112, 12853-12860.

93 R. Boese and O. Heinemann, Z. Kristallogr., 1993, 205, 348-349.

94 A. J. de Vries and J. Kroon, Acta Crystallogr., Sect. C: Cryst. Struct. Commun., 1984, 40, 1542-1544.

95 R. C. Evans, Z. Kristallogr., 1935, 92, 154-155.

96 G. K. Ambady, Acta Crystallogr., Sect. B: Struct. Crystallogr. Cryst. Chem., 1968, 24, 1548-1557.

97 F. C. Hawthorne, I. Borys and R. B. Ferguson, Acta Crystallogr., Sect. B: Struct. Crystallogr. Cryst. Chem., 1982, 38, 2461-2463.

98 P. van der Sluis, A. Schouten and A. L. Spek, Acta Crystallogr., Sect. C: Cryst. Struct. Commun., 1987, 43, 1922-1924.

99 J. Panzer, J. Chem. Eng. Data, 1962, 7, 140-142.

100 C. Saury, R. Boistelle, F. Dalemat and J. Bruggeman, J. Chem. Eng. Data, 1993, 38, 56-59.

101 Z. Yao, H.-T. Kwak, D. Sakellariou, L. Emsley and P. J. Grandinetti, Chem. Phys. Lett., 2000, 327, 85-90.

102 R. Siegel, T. T. Nakashima and R. E. Wasylishen, Concepts Magn. Reson., Part A, 2005, 26, 47-61.

103 F. A. Perras, J. Viger-Gravel, K. M. N. Burgess and D. L. Bryce, Solid State Nucl. Magn. Reson., 2013, 51-52, 1-15.

104 F. C. Hawthorne and R. B. Ferguson, Can. Mineral., 1975, 13, 289-292.

105 C. Bezou, A. Nonat, J.-C. Mutin, A. N. Christensen and M. S. Lehmann, J. Solid State Chem., 1995, 117, 165-176.

106 P. Ballirano, A. Maras, S. Meloni and R. Caminiti, Eur. J. Mineral., 2001, 13, 985-993.

107 W. F. Cole and C. J. Lancucki, Acta Crystallogr., Sect. B: Struct. Crystallogr. Cryst. Chem., 1974, 30, 921-929.

108 G. E. Pake, J. Chem. Phys., 1948, 16, 327-336.

109 W. A. Wooster, Z. Kristallogr., 1936, 94, 375-396.

110 M. Atoji and R. E. Rundle, J. Chem. Phys., 1958, 29, 1306-1311.

111 B. F. Pedersen and D. Semmingsen, Acta Crystallogr., Sect. B: Struct. Crystallogr. Cryst. Chem., 1982, 38, 1074-1077.

112 B. Ravikumar, S. Pandiarajan and S. Athimoolam, Acta Crystallogr., Sect. E: Struct. Rep. Online, 2013, 69, 0596.

113 J. H. Clouse, Z. Kristallogr., 1930, 76, 285-286.

114 J. H. Clouse, Z. Kristallogr., 1932, 83, 161-171.

115 M. A. M. Forgeron and R. E. Wasylishen, Magn. Reson. Chem., 2008, 46, 206-214.

116 H. D. Megaw, Proc. Phys. Soc. London, 1946, 58, 133-152.

117 H. F. Kay and P. C. Bailey, Acta Crystallogr., 1957, 10, 219-226.
118 H. J. A. Koopmans, G. M. H. van de Velde and P. J. Gellings, Acta Crystallogr., Sect. C: Cryst. Struct. Commun., 1983, 39, 1323-1325.

119 S. Sasaki, C. T. Prewitt, J. D. Bass and W. A. Schulze, Acta Crystallogr., Sect. C: Cryst. Struct. Commun., 1987, 43, 1668-1674.

120 X. Liu and R. C. Liebermann, Phys. Chem. Miner., 1993, 20, 171-175.

121 B. J. Kennedy, C. J. Howard and B. C. Chakoumakos, J. Phys.: Condens. Matter, 1999, 11, 1479-1488.

122 T. J. Bastow, P. J. Dirken, M. E. Smith and H. J. Whitfield, J. Phys. Chem., 1996, 100, 18539-18545.

123 D. Padro, V. Jennings, M. E. Smith, R. Hoppe, P. A. Thomas and R. Dupree, J. Phys. Chem. B, 2002, 106, 13176-13185.

124 D. Padro, A. P. Howes, M. E. Smith and R. Dupree, Solid State Nucl. Magn. Reson., 2000, 15, 231-236.

125 B. Ribar and V. Divjaković, Acta Crystallogr., Sect. B: Struct. Crystallogr. Cryst. Chem., 1973, 29, 1546-1548.

126 A. Leclaire and J.-C. Monier, Acta Crystallogr., Sect. B: Struct. Crystallogr. Cryst. Chem., 1977, 33, 1861-1866.

127 A. Leclaire, Acta Crystallogr., Sect. B: Struct. Crystallogr. Cryst. Chem., 1976, 32, 235-238.

128 A. Leclaire, Acta Crystallogr., Sect. B: Struct. Crystallogr. Cryst. Chem., 1976, 32, 1950-1953.

129 L. Vegard, Z. Phys., 1922, 9, 395-410.

130 F. C. Kracek, S. B. Hendricks and E. Posnjak, Nature, 1931, 128, 410-411.

131 E. Zintl and A. Harder, Z. Elektrochem. Angew. Phys. Chem., 1935, 41, 33-52.

132 J. Bergsma and B. O. Loopstra, Acta Crystallogr., 1962, 15, 92-93.

133 A. F. Andresen, A. J. Maeland and D. Slotfeldt-Ellingsen, J. Solid State Chem., 1977, 20, 93-101.

134 J. H. E. Cartwright, A. G. Checa, J. D. Gale, D. Gebauer and C. I. Sainz-Díaz, Angew. Chem., Int. Ed., 2012, 51, 11960-11970.

135 A. F. Wallace, L. O. Hedges, A. Fernandez-Martinez, P. Raiteri, J. D. Gale, G. A. Waychunas, S. Whitelam, J. F. Banfield and J. J. de Yoreo, Science, 2013, 341, 885-889.

136 L. Kabalah-Amitai, B. Mayzel, Y. Kauffmann, A. N. Fitch, L. Bloch, P. U. P. A. Gilbert and B. Pokroy, Science, 2013, 340, 454-457.

137 J. C. Johnston, R. J. Iuliucci, J. C. Facelli, G. Fitzgerald and K. T. Mueller, J. Chem. Phys., 2009, 131, 144503.

138 B. K. Sahoo, Phys. Rev. A: At., Mol., Opt. Phys., 2009, 80, 012515.

139 C. M. Widdifield and D. L. Bryce, Phys. Chem. Chem. Phys., 2009, 11, 7120-7122.

140 F. A. Perras and D. L. Bryce, J. Phys. Chem. C, 2012, 116, 19472-19482.

141 N. F. Ramsey, Phys. Rev., 1950, 78, 699-703.

142 N. F. Ramsey, Phys. Rev., 1951, 83, 540-541.

143 N. F. Ramsey, Physica, 1951, 17, 303-307.

144 C. M. Widdifield and R. W. Schurko, Concepts Magn. Reson., Part A, 2009, 34, 91-123.

145 D. L. Bryce and R. E. Wasylishen, Phys. Chem. Chem. Phys., 2002, 4, 3591-3600. 